\title{
Sea breeze thunderstorms in the eastern Iberian Peninsula. Neighborhood verification of HIRLAM and HARMONIE precipitation forecasts
}

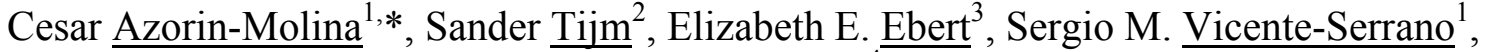 \\ María J. Estrela ${ }^{4}$ \\ Surnames (or family names) are underlined \\ 1. Instituto Pirenaico de Ecología, Consejo Superior de Investigaciones Científicas (IPE-CSIC), \\ Departamento de Procesos Geoambientales y Cambio Global, Avda. Montañana 1005, \\ 50059-Zaragoza, Spain
}

2. Royal Netherlands Meteorological Institute (KNMI), PO Box 201, NL-3730 AE De Bilt, The Netherlands

3. Centre for Australian Weather and Climate Research (CAWCR), Bureau of Meteorology, GPO Box 1289, VIC 3001 Melbourne, Australia

4. Laboratory of Meteorology-Climatology, Mixed Unity CEAM-UVEG, Department of Physical Geography, University of Valencia, Avda. Blasco Ibáñez 28, 46010-Valencia, Spain

\footnotetext{
* Corresponding author at: Instituto Pirenaico de Ecología, Consejo Superior de Investigaciones Científicas (IPE-CSIC), Departamento de Procesos Geoambientales y Cambio Global, Avda. Montañana 1005, 50059-Zaragoza, Spain. Tel.: (+34) 97.671.60.34 ; fax: $(+34) 97.436 .32 .22$ E-mail address: cazorin@ipe.csic.es (C. Azorin-Molina)
} 
36 In this study we investigated sea breeze thunderstorms with intense convective activity

37 (i.e., heavy rainfall, hail and gusty winds) that occurred over the eastern Iberian

38 Peninsula (Spain) and were missed by the operational HIRLAM model. We used two

39 grid-spacing setups $(5.0-\mathrm{km}$ and $2.5-\mathrm{km})$ of the hydrostatic HIRLAM model, and the

40 non-hydrostatic spectral HARMONIE suite $(2.5-\mathrm{km})$, to simulate isolated convection

41 associated with sea breezes. The overall aim is to estimate the ability of these three

42 experimental setups, in particular the HARMONIE model as the forthcoming

43 operational Numerical Weather Prediction in most European Weather Services, to

44 correctly simulate convective precipitation associated with sea breezes. We evaluated

45 high-resolution gridded precipitation forecasts from HIRLAM and HARMONIE suites

46 for 15 sea breeze thunderstorms against high-density gridded raingauge measurements

47 applying different neighborhood verification techniques. The results indicate that

48 higher horizontal resolutions of HIRLAM and HARMONIE models succeeded in

49 predicting the occurrence of these missed sea breeze thunderstorms, the HARMONIE

50 suite being the most capable of providing good estimates of accumulated precipitation

51 in convective events in terms of space and time. Advances in quantitative precipitation

52 forecasting of locally driven convection could have practical applications for

53 nowcasting dangerous sea breeze convective phenomena.

54 Keywords: sea breeze thunderstorm; operational forecasting; HIRLAM; HARMONIE; neighborhood verification; Iberian Peninsula. 


\section{Introduction}

The effect of sea breezes in triggering deep convection has been noted in numerous coastal areas around the world (Simpson, 1994). Many numerical modelling and observational studies, particularly for the subtropical Florida Panhandle (e.g.,

62 Pielke, 1974; Pielke and Cotton, 1977; Pielke and Mahrer, 1978; Blanchard and Lopez, 1985; Nichols et al., 1991; Wakimoto and Atkins, 1994), found that low-level sea breeze convergence and consequently sea breeze front (SBF) development enhance planetary boundary layer (PBL) air parcels to lift up to the level of free convection (LFC) (Wilson, 2008; Muppa et al., 2012). Convective initiation can also occur from horizontal convective rolls (HCR) ahead of the advancing SBF (Atkins et al., 1995). Both SBF and HCR updrafts merge, promoting deep convective sea breeze thunderstorms that can sometimes be extraordinarily severe, causing significant rainfall, hail and gusty winds along the frontal boundary (Dailey and Fovell, 1999; Fovell and Dailey, 2001; Fovell, 2005). intensified by several factors (Simpson et al., 2007). The most relevant are as follows: (a) anabatic valley wind circulations on heated south-facing mountain slopes play a major role in strengthening uplift processes and developing deep convection by combining with moist sea breezes that transport water vapor to the coastal mountains in the daytime (Millan et al., 2005); (b) convergence and SBF intensification is also enhanced by frictional effects (upslope orographic lifting) produced in coastal areas of complex terrain (Petterssen, 1956; Pérez-Landa et al., 2006; Papanastasiou et al., 2010);

80 (c) strong low-level sea breeze convergence also occurs on convex coastlines (e.g., 
81 peninsulas, capes, points, and also islands) contributing to increased upward vertical

82 motion, Cumulus $(\mathrm{Cu})$ and Cumulonimbus $(\mathrm{Cb})$ activity and thunderstorms along the

83 frontal area (Neumann, 1951; Pielke, 1974; Purdom, 1976; Strickler, 2003); (d) a

84 sharply defined discontinuity and convergence intensification is observed inland along

85 the SBF under offshore large-scale synoptic flows (Bechtold et al., 1991; Atkins and

86 Wakimoto, 1997), and light to moderate winds aloft $\left(<5.0 \mathrm{~m} \mathrm{~s}^{-1}\right)$ result in more clouds at

87 the leading edge of sea breezes (Azorin-Molina et al., 2009); and (f) regions of high soil

88 moisture expect heavy precipitation along the SBF (Baker et al., 2001). Most of the

89 aforementioned factors interact over the complex eastern façade of the Iberian Peninsula

90 (Spain), where thermally induced local circulations interact.

91 Short-term forecasting of the timing, location and intensity of isolated sea breeze

92 thunderstorms represents a challenging task in numerical weather prediction (NWP),

93 mainly due to the uncertainties in the initial conditions, limited knowledge about the

94 cloud microphysical processes, and difficulties in resolving low-level sea breeze

95 convergence and convection with fairly coarse horizontal resolution operational NWP

96 models (Mazarakis et al., 2009). Furthermore, isolated sea breeze thunderstorm cells

97 with severe weather can develop unexpectedly under weakly defined synoptic-scale or

98 mesoscale precursor disturbances (Wilson, 2008), and may be missed by forecasts.

99 Strong low-level sea breeze boundaries can deliver enough energy to overcome the

100 stable cap of the PBL and generate local showers and thunderstorms unexpectedly. For

101 instance, deep convection associated with sea breezes can occur even when sounding

102 indices indicate stable weather conditions. This is because sounding indices do not

103 consider layers below $850 \mathrm{hPa}$, where strong low level convergence may accumulate

104 lower tropospheric moisture (Pielke et al., 1971) or capping of inversions can occur,

105 enhancing or weakening lifting mechanisms, respectively. 
107 (May-September), but also in the transition months of April and October, over the 108 complex eastern façade of the IP. Its time of occurrence is nearly always in the mid-

109 afternoon. Despite the high level of occurrence of thermally-driven winds (sea breezes

110 blow two out of three days of the year, Azorin-Molina and Martin-Vide, 2007) and also

111 that sea breeze convection brings an average of $100-125 \mathrm{~mm}$ yearly to inland areas

112 during the summer dry season (Millan et al., 2005), there is little knowledge concerning

113 the important role that sea breezes play in convection initiation in the eastern coast of

114 Spain. A review of these few investigations was presented by Azorin-Molina et al.

115 (2009), who used high-resolution cloud frequency composites derived from NOAA-

116 AVHRR data to identify the location of five preferential sea breeze convergence zones

117 (SBCZ; hot spots) in the Iberian Mediterranean area and the Isle of Mallorca. The

118 current study is focused on two of them, i.e., the SBCZ2 (eastern region of the Iberian

119 system mountains; 1000-1900 m) and the SBCZ3 (Prebetic mountain ranges; 1000-

$1201600 \mathrm{~m}$ ). These regions correspond to the east of the Iberian Peninsula, an

121 orographically highly complex area (Figure 1a).

The main goal of this study is to estimate the ability of NWP to correctly simulate convective precipitation associated with sea breezes. Two different setups

124 (5.0-km and 2.5-km horizontal grid-spacing) of the operational HIRLAM model and

125 the non-hydrostatic spectral HARMONIE suite (2.5-km horizontal grid-spacing; Hirlam

126 Aladin Regional/Meso-scale Operational NWP In Europe) are evaluated. Three

127 different neighborhood (also known as 'fuzzy') verification techniques are applied here

128 in order to measure the strength of the HIRLAM and HARMONIE agreement with the

129 observations. The article is structured as follows. In section 2, we summarize the model

130 description, set up and initialization of HIRLAM and HARMONIE suites, present the 
131 sea breeze thunderstorms simulated and observed precipitation data, and briefly

132 describe the neighborhood verification methods applied in this study. In section 3 , the performance of HIRLAM and HARMONIE gridded precipitation forecasts is evaluated against gridded precipitation observations. In section 4 , the sea breeze thunderstorm

135 occurred on 7 August 2008 is analyzed. Finally, a summary and discussion of the

136 findings from this study are presented in section 5.

\section{Data and methods}

\subsection{HIRLAM and HARMONIE model description, set up and initialization}

The NWP systems used here are the three-dimensional hydrostatic grid-point model version 7.2.2 of HIRLAM (Undén et al., 2002), and the non-hydrostatic spectral model version 36h1.2 of HARMONIE (Seity et al., 2011). The HIRLAM short-range

143 forecasting model was chosen for this research because it is currently employed as one

144 of the most important operational NWP system at the AEMET, and by eight other

145 European Weather Services: Denmark, Estonia, Finland, Iceland, Ireland, the

146 Netherlands, Norway and Sweden. The HARMONIE limited area model is also used in

147 this study because it will be implemented shortly as the operational NWP in most of the

148 European Weather Services. Actually, it is currently being evaluated as a next-

149 generation replacement for HIRLAM (van der Plas et al., 2012; de Brujin and de Rooy, 150 2012).

The dynamical core of HIRLAM model is based on a semi-implicit semi-

152 Lagrangian discretization of the multi-level primitive equations, employing a hybrid

153 coordinate in the vertical. The comprehensive set of physical parameterization schemes 
154 selected in the HIRLAM model suite in order to take into account a variety of sub-

155 gridscale physical processes include: (a) a radiation scheme (Savijärvi, 1990), (b) an

156 adapted Rasch-Kristjansson condensation (Zhang et al., 2003; Ivarsson, 2007) and a

157 Kain-Fritsch mass-flux convection scheme with CAPE closure (Kain, 2004; Calvo,

158 2007), (c) a prognostic moist turbulent kinetic energy (TKE) parameterization (Tijm

159 and Lenderink, 2003), (d) a tiled surface approach distinguishing seven surface types

160 (Interaction Soil-Biosphere-Atmosphere, ISBA surface scheme, Noilhan and Planton,

161 1989; snow and forest, Gollvik, 2002, 2004; lake, Mironov, 2008, Kourzeneva et al.,

162 2008), and (e) a mean and subgrid-scale orography parametrization (Rontu et al., 2002).

163 The HIRLAM system also includes a 4D-VAR data assimilation system (Huang et al.,

164 2002) with analysis of conventional and non-conventional observations. More detailed

165 descriptions about the dynamical and numerical features of the HIRLAM short-range

166 forecasting model can be found in Undén et al. (2002) and at the following URL:

167 http://hirlam.org/index.php?option=com_content\&view=article\&id=64:general-

168 description-of-the-hirlam-model\&catid=48: synoptic-scale-model-hirlam\&Itemid=101

169 (last accessed 1 November 2013).

170 The HARMONIE model suite is designed in a cooperation between the

171 HIRLAM and ALADIN (Aire Limitée Adaptation dynamique Développement

172 InterNational) consortia. The dynamical core of the mesoscale model HARMONIE is

173 developed by ALADIN high precision short-range NWP model and based on a two-

174 time level semi-implicit semi-Lagrangian discretization of the fully elastic equations,

175 also employing a hybrid coordinate in the vertical. ALADIN is a spectral limited-area

176 model developed at Météo-France and based on the ARPEGE/IFS model. The

177 HARMONIE mesoscale option consists of a combination of ALADIN's non-hydrostatic

178 dynamics and Mesoscale Non-Hydrostatic atmospheric model (NH; 
179 http://mesonh.aero.obs-mip.fr/mesonh410; last accessed 1 November 2013) physics.

180 The parametrizations of a variety of sub-gridscale physical processes are the same as 181 those adopted of the AROME physics (Seity et al., 2011). The HARMONIE system

182 includes a 3D-VAR data assimilation system. A more detailed description of the

183 HARMONIE model can be found at this URL:

184 http://hirlam.org/index.php?option $=$ com content\&view $=$ article\&id $=65 \&$ Itemid $=102$

185 (last accessed 1 November 2013).

Here, we are interested in evaluating the precipitation performance of the HIRLAM $0.05^{\circ}$ (4.3-km length; hereafter HIR-D5) horizontal grid-spacing against a higher horizontal grid-resolution of HIRLAM $0.025^{\circ}$ (2.5-km length; hereafter HIRD2.5) and HARMONIE $0.025^{\circ}$ (2.5-km length; hereafter HAR-D2.5), for those sea breeze thunderstorm episodes described in section 2.2. On the one hand, the HIRLAM model is set up with unique domains with an integration area of $300 \times 306$ horizontal grid points (latitude by longitude) and the size of $1495 \mathrm{~km}$ x $1525 \mathrm{~km}$ for the HIR-D5 experiment, and $400 \times 406$ horizontal grid points and $997.5 \mathrm{~km} \times 1012.5 \mathrm{~km}$ for the HIR-D2.5 experiment. Increased boundary layer vertical resolution can provide improved forecast performance (Ries and Heinke-Schlunzen, 2009), and therefore the vertical domain for the two set ups of the HIRLAM contains 60 sigma levels with enhanced resolution (27 levels in the lowest $3 \mathrm{~km}$ ) in the PBL. The model top is at 10 $\mathrm{hPa}$ and the lowest model level is around $32 \mathrm{~m}$. On the other hand, the HAR-D2.5 experiment is set up with an integration area of $400 \times 400$ horizontal grid points

200 (latitude by longitude) and the size of $1000 \mathrm{~km} \times 1000 \mathrm{~km}$, also employing a vertical domain of 60 hybrid levels with enhanced resolution (27 levels in the lowest $3 \mathrm{~km}$ ) in the PBL. The HARMONIE model top is at $1 \mathrm{hPa}$ and the lowest model level is around $10 \mathrm{~m}$. The ECMWF archive supplies the operational boundaries data for both HIRLAM 
and HARMONIE suites with a horizontal grid-spacing of $0.5^{\circ} \times 0.5^{\circ}$ and a temporal

205 resolution of $6 \mathrm{~h}$. These boundaries are also applied as initial conditions. Lateral

206 boundaries are overspecified, all variables being externally prescribed by the nesting

207 model. A relaxation zone of 10 grid points is normally adopted and boundary relaxation

208 is performed after the horizontal diffusion. Additionally, at the upper boundary a

209 condition of zero vertical velocity is imposed. The dynamics time step is $120 \mathrm{~s}$ for the

210 HIR-D5, and $60 \mathrm{~s}$ for the HIR-D2.5 and the HAR-D2.5 experiments. All the

211 simulations were initialized at 1200 UTC the day before the sea breeze thunderstorm

212 event, and integrated for $48 \mathrm{~h}$ until 1200 UTC the day after the episode, with model

213 outputs at intervals of $1 \mathrm{~h}$. The domains for each NWP system are represented in Figure

$2141 b$.

215

216

\subsection{Simulated sea breeze thunderstorms and observed precipitation data}

We exclusively focused on 15 deep convective sea breeze thunderstorms that were missed by the operational HIRLAM model; i.e., 'observed but not forecasted episodes'. A detailed verification of 'forecasted but not observed events' (i.e., false alarms) is also an interesting topic for future work, but is out of the scope of this study

221 aimed in analyzing the ability of hydrostatic and non-hydrostatic convection-permitting

222 models in resolving these sea breeze thunderstorms.

These thunderstorms corresponded to typical sea breeze fronts that developed explosively under weakly defined synoptic-mesoscale forcing; i.e., weak surface pressure gradient in the western Mediterranean basin. Some of these storms were severe, causing significant amounts of rainfall, hail and gusty winds. This synoptic 
227 pattern allowed the inflow of moisture driven by well-developed local thermal

228 circulations, which mainly triggered these storms at the low-level convergence zone of

229 sea breezes. All these convective events were isolated and stationary as was revealed in

230 the geostationary and polar satellite images, Doppler radar, and lightning data. Table I

231 summarizes the list of sea breeze thunderstorms simulated, the number of raingauge

232 station points used for the neighborhood verification, and the maximum of precipitation

233 recorded for each episode at 06 UTC.

With the aim to evaluate the performance of HIRLAM versus HARMONIE

precipitation forecasts of these sea breeze thunderstorm episodes, this research used 24

236 h-precipitation accumulations (from 0800 UTC till 0800 UTC) from a high-density

237 network of Hellman-type raingauges covering the eastern region of the IP (Figure 1b).

238 The observed precipitation data have been supplied mainly by the AEMET, but we also

239 used a small number of observations from automatic weather stations (AWS; tipping

240 bucket raingauges) collected from the Mediterranean Center for Environmental Studies

241 (CEAM; http://www.ceam.es/index i.htm; last accessed 1 November 2013), the

242 Automatic System of Hydrological Information of the Ebro basin management agency

243 (SAIH; http://www.saihebro.com/saihebro/index.php; last accessed 1 November 2013),

244 the Valencian Institute for Agriculture Research (IVIA; http://www.ivia.es/; last

245 accessed 1 November 2013), the Agro-climatic Information System for Irrigation

246 (SIAR, http://crea.uclm.es/siar/; SIAM, http://siam.imida.es/; last accessed 1 November

247 2013) and the METEOCLIMATIC network (http://www.meteoclimatic.com/; last

248 accessed 1 November 2013). The high-density raingauge network consists of a

249 minimum of 304 and a maximum of 533 observation points depending on each episode

250 and covers an area bounded between $37^{\circ} 00^{\prime} \mathrm{N}$ and $41^{\circ} 00^{\prime} \mathrm{N}$ and $3^{\circ} 00^{\prime} \mathrm{W}$ and $1^{\circ} 00^{\prime} \mathrm{E}$, i.e.

251 both sea breeze convergence zones (SBCZ2 and SBCZ3; see Fig. 1a) with intensified 
252 convective activity. Since data were obtained from various institutions, the $24-\mathrm{h}$ raw

253 accumulated precipitation passed quality control (Aguilar et al., 2003) based on

254 removing gross errors due to archiving, transcription and digitalization. This basically

255 consisted on screening out suspicious precipitation values (outliers), such as extreme

256 and large values for 10-minute, 30-minute or daily measurements.

The precipitation forecasts and observations were gridded onto a regular grid with dimensions of $81 \times 81$ grid points for the $5-\mathrm{km}$ runs, and $161 \times 161$ for the $2.5-\mathrm{km}$ runs, resulting in a grid forecast and grid observation with the same dimensions for each episode and model run. For gridding the observations into a regular grid we placed the

261 point observation values at the grid points closest to the observation points. When more

262 than one observation was present in a grid box of the single intercomparison grid, which occurred for only two grid points in the total 15 sea breeze thunderstorms, the highest value was chosen. Here we compared 24 h-precpitation accumulations (from 08:00 UTC till 08:00 UTC) from the gridded simulated and observed precipitation boxes.

\subsection{Neighborhood or 'fuzzy' verification methods}

The statistical verification of high-resolution gridded precipitation forecasts such as those from HIRLAM and HARMONIE model suites against raingauge data is

270 increasingly conducted by applying neighborhood or 'fuzzy' methods. We decided to

271 use this approach because traditional verification metrics (e.g., mean square error, root

272 mean square error, etc.) typically give poor and uninformative values for high resolution

273 forecasts of small-scale features (e.g., low-level convergence of sea breezes triggering

274 isolated convection) since exact matches between forecasts and observations are quite 
275 difficult to achieve (Ebert, 2008). However, neighborhood methods use a spatial

276 window or neighborhood surrounding the forecast and observed points and therefore

277 relax the condition for exact matches between forecasted and observed precipitation in

278 space, time and intensity.

Three of the single observation-neighborhood forecast approaches are used here

280 for evaluating the precipitation performance of the HIRLAM and the HARMONIE

281 simulations during the 15 sea breeze thunderstorm events ('observed but not forecast

282 episodes'). The three methods compare a neighborhood of forecast values to the

283 observation in the centre of the neighborhood. This mimics how a forecaster might

284 interpret high resolution model outputs when making a prediction for a particular

285 location. These particular methods were selected to assess the frequency of the forecasts

286 predicting appropriately high rainfall near the observed location, and to evaluate the

287 spatial scales over which a forecaster might consider the model output to be useful.

The first neighborhood technique corresponds to the 'multi-event contingency

table' proposed by Atger (2001), which measures the closeness of the forecasted

precipitation to the raingauge observations for multiple decision intensity, spatial and temporal thresholds. Basically, the 'multi-event contingency table' builds on the traditional $2 \times 2$ contingency table, in which hits, misses, false alarms, and correct rejections are counted for forecasted and observed occurrences of an event (for

294 precipitation an event is usually defined as rain exceeding a given intensity threshold).

295 The method combines the customary intensity dimension with additional thresholds

296 such as spatial and temporal closeness. The method is based on the criterion that a

297 forecast is useful if the event is forecasted in at least one grid box within a specified

298 distance $s$ of an observed event. If that is the case, then the forecast is counted as a hit; if 
not, then the forecast is a miss. Forecasts for rain within a distance $s$ of a location where

300 rain was not observed are counted as false alarms. success of the precipitation forecasts. The HK score (also known as true skill statistics TSS- and Peirce's skill scoce -PSS-) represents a balance between the hit rate (H) and

304 false alarm rate $(F)$, i.e., $\mathrm{HK}=\mathrm{H}-\mathrm{F}$, with a perfect value of 1 :

$$
H=\frac{\text { hits }}{\text { hits }+ \text { misses }} \quad \text { (1) } \quad F=\frac{\text { false alarms }}{\text { correct rejections }+ \text { false alarms }}
$$

307 technique defined by Theis et al. (2005) which uses the observed precipitation in the

308 central grid box as a value to verify the model performance against the forecast

309 precipitation probability within a neighborhood. A useful forecast has skill at detecting

310 precipitation events and non-events, that is, it has high probabilities in the vicinity of

311 observed events and low probabilities in the vicinity of observed non-events. The

312 probabilistic verification metric corresponds to the Brier skill score (BSS) with respect

313 to the sample climatology. The reference forecast (i.e., the forecast to beat) is the

314 fraction of observations over the whole domain with rain meeting or exceeding the

315 threshold.

$$
B S S=1-\frac{\frac{1}{N} \sum_{N}\left(\left\langle P_{y}\right\rangle_{s}-I_{x}\right)^{2}}{\frac{1}{N} \sum_{N}\left(\overline{P_{x}}-I_{x}\right)^{2}}
$$

317 where $N$ is the number of observation locations, $I_{x}$ is an indicator ( $1=$ yes, $0=$ no) for an

318 observed event at each location, $\left\langle P_{y}\right\rangle_{s}$ is the fraction coverage of forecast events within 
319 the neighborhood of radius $s$, and $\bar{P}_{x}$ is the domain mean value of $I_{x}$. BSS varies

320 between minus infinity and 1, with larger values indicating more skillful forecasts.

323 Zawadzki (2004). The definition of a useful forecast according to this metric is one with

324 a high probability of matching the observed precipitation value. This method is based

325 on the computation of the ranked probability score (RPS), which uses the frequencies of

326 forecast precipitation values in logarithmically increasing intervals. The RPS quantifies

327 the sum of squared differences in cumulative probability space for a multi-category

328 probabilistic forecast (e.g., Wilks, 2011):

$$
R P S=\frac{1}{M-1} \sum_{m=1}^{M}\left(C D F_{y, m}-I_{x, m}\right)^{2}
$$

330 where $M$ is the number of forecast categories, $\mathrm{CDF}_{y, m}$ is the cumulative probability of

331 the forecast exceeding the threshold for category $m$, and $I_{x, m}$ is 1 if the observed rainfall

332 meets or exceeds the threshold for category $m$ and 0 if not. The square root of the RPS

333 is the standard error of the forecast probability in probability space, and therefore values

334 closer to 0 indicate better forecasts. In order to compare different rainfall episodes the

335 square root of the RPS is normalized by the observed rain fraction.

$$
C S R R=\frac{\sqrt{R P S}}{\overline{P_{x>0}}}
$$

All three fuzzy methods were applied to the individual gridded forecasts. For each method and model-observation category, the results were aggregated over all cases 
and plotted both as a function of neighborhood size and as quilt plots. The window sizes

340 were $1 \times 1,3 \times 3,5 \times 5$, up to $25 \times 25$, only plotting results for spatial scales from 2.5 up to

$34197.5-\mathrm{km}$. The rainfall thresholds used to define events and categories (needed by the

342 various scores) were $0.2,1.0,2.0,5.0,10.0,20.0$, and $50.0 \mathrm{~mm}$, where an event is

343 defined as the rain equal to or exceeding the threshold. A more detailed description of

344 these three neighborhood verification techniques and metrics can be found in the review

345 article of Ebert (2008).

346 In section 3 we present neighborhood verification results for all the 15 sea

347 breeze thunderstorms and show an example of good high-resolution precipitation

348 forecast performance for an isolated sea breeze thunderstorm developed over the Iberian

349 System Mountains (ISM) on 7 August 2008.

\section{Results}

\subsection{Rain distribution from gridpoint match-ups}

The rain distribution plot displayed in Figure 2 shows that all three high-

resolution gridded rainfall forecasts overestimate the observed point precipitation intensity distribution, with the HIR-D2.5 having a slightly greater over-prediction bias than the coarser HIR-D5 model. The HAR-D2.5 did a much better job of representing the observed rain amount distribution. The models also differed in their ability to predict the maximum rainfall. For instance, forecast rain accumulations exceeding 20 $\mathrm{mm}$ are uncommon in the HIR-D5 (sample maximum of $22 \mathrm{~mm}$ ), whereas the higher

360 resolution models produced much higher rain accumulations (sample maxima of 113

$361 \mathrm{~mm}$ for HIR-D2.5 and $64 \mathrm{~mm}$ for HAR-D2.5). The observed maximum rain amount 
362 was $90 \mathrm{~mm}$ (see Table 1). The overprediction bias has an impact on the neighborhood

363 scores discussed below.

\subsection{Multi-event contingency table method}

The multi-event contingency table technique, which checks whether a

367 precipitation forecast event is found near an observed value, suggest that the HIRLAM

model provided better forecasts than the HARMONIE model when low rain thresholds

were chosen, but for precipitation exceeding about $5 \mathrm{~mm}$ the HARMONIE model

performed more reasonably. This overall feature is clearly discernible looking at the quilt plots shown in Figure 3 which display the HK metric for different rain intensity thresholds $(0.2,1.0,2.0,5.0,10.0,20.0$ and $50.0 \mathrm{~mm} ; x$-axes $)$ as a function of various window sizes (from 2.5 up to $97.5-\mathrm{km}$; $y$-axes). The magnitude of HK score is plotted and the shade gives an idea of the model's performance, i.e., darker (orange colors) and lighter (blue colors) shades represent better and poorer skills, respectively. In addition, an intensity dependent skillful scale can be obtained by drawing a line through the better score in the verification HK results as shown in Figure 3. Table 2 compares the skillful scales and accompanying HK scores for three models. From the quilt plots and table we can conclude that for rain thresholds of $5.0 \mathrm{~mm}$ and greater, the optimal scale

380 for the HARMONIE model is smaller than for the HIRLAM suites, meaning that one

381 needs to look over a smaller distance to find a forecast matching the observation,

382 without having too many false alarms for non-events. For instance, the $0.2 \mathrm{~mm}$ rain

383 threshold is best achieved at grid scale by the HIR-D2.5 (2.5 km; HK 0.34; Figure 3a)

384 and the HIR-D5 (5.0 km; HK 0.31; Figure 3b), and at a slightly higher scale but with

385 greater accuracy by the HAR-D2.5 (7.5 km; HK 0.37; Figure 3c). Higher horizontal grid 
resolution for both the HIR-D2.5 and the HAR-D2.5 is crucial for obtaining smaller

387 optimal scales for rain intensity thresholds equal or greater than $1.0 \mathrm{~mm}$ in comparison

388 to the coarser HIR-D5. The optimal scales and HK scores found for the rain threshold of

$38950.0 \mathrm{~mm}$ are not representative since there were only 3 observations exceeding this

390 intensity.

Comparing the $2.5-\mathrm{km}$ models the HAR-D2.5 model outperformed the HIR-

D2.5 model for most rainfall thresholds and scales, with HIR-D2.5 only scoring better than HAR-D2.5 at the finest $2.5-\mathrm{km}$ grid scale and large scales for $10-20 \mathrm{~mm}$ rain thresholds. These results confirm the improved ability of the forthcoming nonhydrostatic convection-permitting HARMONIE model suite as an operational NWP model to capture isolated convection associated with mesoscale / local winds.

\subsection{Pragmatic method}

The BSS is used as a metric for the pragmatic neighborhood verification

400 technique in order to test how useful forecasts are in detecting events and non-events.

401 The reference forecast (i.e., the forecast to beat) is the fraction of observations in each

402 case that are events (i.e., the sample climatology over the whole domain). Figure 4

403 shows the quilt diagrams where the magnitude of the BSS metrics is plotted as a

404 function of the aforementioned intensity precipitation thresholds ( $x$-axes) and the range

405 of spatial scales ( $y$-axes). In general, the pragmatic method suggests that the forecasts

406 had poor skill for most rain rates and scales, with the HARMONIE scheme performing

407 best according to the BSS scores. To resolve this apparent contradiction in comparison

408 to the reasonable HK scores shown in Figure 3, it is important to recognize that both 
neighborhood methods are addressing different questions; the pragmatic approach is a

410 much tougher test than the "at least one nearby forecast event". Because all three

411 models over-predicted the number of rain events, it was difficult to beat the sample

412 climatology and the skill was negative for all scales and thresholds as shown in Figures

413 4a (HIR-D2.5), 4b (HIR-D5) and 4c (HAR-D2.5), and summarized in Table 3. We can

414 conclude that, according to this score, poorer performance occurred at small scales and

415 low to moderate thresholds. This skill according to the BSS metric was poorer for HIR-

416 D2.5 than for HIR-D5, while the HAR-D2.5 had the best performance due partly to its

417 more appropriate rain intensity distribution.

\section{3.4. Conditional square root of RPS}

The conditional square root of RPS method, which is an error metric with a

421 perfect value of 0 , also showed the best performance for the HAR-D2.5, followed by the

422 HIR-D5 and the HIR-D2.5. As with the pragmatic method, the CSRR scores improve

423 when increasing to larger scales as shown in Figure 5. This method rewards forecasts

424 that have a peak in the (neighborhood-based) probability density function that is close to

425 the observed value. The threshold dependence is integrated into the overall score

426 through the forecast PDF. The forecast precipitation for the HIR-D2.5 tended to be

427 higher than for the HIR-D5 and the HAR-D2.5, which means that the forecast PDF

428 peaked even further away from the observation (see Fig. 2). 


\subsection{Observational data}

432 The case study corresponds to a typical SBF that was not forecasted by the operational

433 HIRLAM numerical weather prediction and occurred over the Iberian system mountains

434 (SBCZ2) on 7 August 2008. We chosen this particular event because the highest

435 availability of grid observation points (i.e., 533 gauges; see Table 1) which helped for

436 better evaluating the performance of HIRLAM and HARMONIE forecasts. This non-

437 forecasted sea breeze thunderstorm produced severe convective activity with heavy

438 showers, large hail up to $3.5 \mathrm{~cm}$ in diameter, and gusty winds, causing significant

439 damage in some fruit groves and irrigated areas for vegetables, and also damaged

440 vehicles. The precipitation map displayed in Figure 6 confirms that the study case

441 corresponded to a very isolated sea breeze thunderstorm cell which accumulated

442 significant rainfall over a small area in the SBCZ2. For instance, 40 out of the 533 rain-

443 gauge points, i.e. $7.5 \%$, measured precipitation $\geq 0.1 \mathrm{~mm}$, whereas just 6 meteorological

444 stations reported rainfall $\geq 10.0 \mathrm{~mm}$ : Catí-Meteoclimatic $(45.0 \mathrm{~mm})$, Vallivana-CEAM

445 (27.8 mm), Morella-CHE (15.8 mm), Vallibona-CHJ (11.2 mm), Catí-CHJ (11.2 mm), 446 and El Boixar (10.0 mm).

\subsection{Operational weather forecast}

For the 7 August 2008 experiment the operational HIRLAM model used at the

450 AEMET was version 6.1.2 with a European domain of $0.16^{\circ}$ (16-km length) to simulate

451 the large scale meteorological conditions, and an inner domain with fine resolution of

$452 \quad 0.05^{\circ}$ (5-km length) for the Iberian Peninsula and the Balearic Islands; 40 full sigma

453 levels in the vertical direction were used. The operational HIRLAM 6.1.2 version from

454 the AEMET partly failed in predicting this sea breeze thunderstorm, as is shown for 
455 both the $0.16^{\circ}$ (Figure $7 \mathrm{a}$ ) and the $0.05^{\circ}$ (Figure $7 \mathrm{~b}$ ) domains, where the $0.16^{\circ}$ run gave

456 some light showers and the high resolution run did not produce any precipitation at all.

\subsection{HIRLAM and HARMONIE performance}

Figure 8 shows 24 -h accumulated precipitation forecasts for the same integration time from the HIR-D5 (Fig.8a), the HIR-D2.5 (Fig. 8b), the HAR-D2.5

(Fig. 8c), and (d) the HAR-D2.5 (Fig. 8d) with a factor of 5 increase in precipitation

fall speed. Both the HIRLAM and the HARMONIE research simulations succeeded in capturing the occurrence of convective showers over the SBCZ2 in comparison to the operational HIRLAM model version 6.1.2. However, the HIR-D5 run predicted a weak widespread precipitation signal and displaced far to the northwest; the HIR-D2.5 run simulated heavier rainfall over a larger area located far to the north; and the HAR-D2.5 run forecasted the precipitation at the right place with a reasonable amount. For instance, the precipitation maxima accumulated in $24 \mathrm{~h}$ was $6.6 \mathrm{~mm}$ for the HIR-D5, $92.5 \mathrm{~mm}$ for the HIR-D2.5, and $28 \mathrm{~mm}$ for the HAR-D2.5; the observed maximum was $45.0 \mathrm{~mm}$ in the Cati station. Forecast rain accumulations exceeding $45.0 \mathrm{~mm}$ were not uncommon in the HIR-D2.5 model (seven grid-points sampled 24-h accumulated precipitation greater than this threshold), whereas the maximum 24-h gridded rain accumulations in the HIR-D5 model were less than $10 \mathrm{~mm}$. In contrast, the HAR-D2.5 produced a reasonable number of grid-points with maximum rain accumulations similar to the observations. Summarizing, the HIR-D2.5 version tended to strongly overestimate precipitation at the rain-gauge points; the HIR-D5 version tended to strongly underestimate rainfall at rain-gauge points; and the HAR-D2.5 version performed better precipitation forecasts than both HIRLAM set-ups in terms of amount 
and location, because it correctly reproduced the heavy rainfall along the sea breeze

480 boundary. We also tested the hypothesis that a large part of the overestimation of HIR-

481 D2.5 in comparison to HAR-D2.5 is associated with the fact that the fall speed is

482 infinity in the HIRLAM model suite, i.e., precipitation is put on the ground directly,

483 which is quite normal in hydrostatic models until recently. This was investigated by

484 increasing the fall speed of the rain, snow and graupel by a factor of 5 for the HAR-

485 D2.5 model suite. Fig. 8d shows a significant increase of precipitation by a factor of 2

486 or more over a large part of the precipitation covered area in Fig. 8c, with a maximum

487 precipitation of $55 \mathrm{~mm}$ whereas the original run produced a maximum precipitation

488 amount of $28 \mathrm{~mm}$. This difference can be explained by the increase in fall speed as this

489 reduces the water loading of parcels in the updraft of the showers, increasing the

490 updraft wind speed and associated precipitation formation. Additionally, precipitation

491 spends less time in unsaturated air beneath the cloud, causing less evaporation of this

492 precipitation.

Examination of the wind field shown in Figure 9 reveals that the three model

494 setups resolved the development of a well-defined low-level convergence of sea

495 breezes (easterly-southeasterly flows from the Mediterranean sea) and synoptic flows

496 (westerly-southwesterly flows over the lower plateau of the IP). This convergence zone

497 played a major role in initiating severe weather on the afternoon of 7 August 2008.

498 However the location and strength of the low-level convergence of sea breezes is

499 determined by the model resolution, and this could hypothetically explain why the

500 position of the precipitation is much better in the HAR-D2.5 than in HIR-D5 and HIR-

$501 \quad$ D2.5. 
503 time (Weusthoff, 2011), but time-series plots represent a way to look at the agreement 504 between HIRLAM and HARMONIE model results and the observations in terms of

505 timing. However, for this case-study significant precipitation amounts (i.e., $\geq 5.0 \mathrm{~mm}$ )

506 were available in only three AWS, which are shown in Figure 10. Here we compared

507 the hourly observed precipitation against the maximum modelled precipitation in an

508 area with radius of 5-km around the AWS. For the Vallivana-CEAM station $(27.8 \mathrm{~mm}$;

509 Fig. 9a) both the HIR-D5 and the HIR-D2.5 did not capture the hourly maxima of

510 precipitation that occurred at $15 \mathrm{UTC}(15.0 \mathrm{~mm})$ and $16 \mathrm{UTC}(12.7 \mathrm{~mm})$, whereas the

511 HAR-D2.5 correctly predicted the timing and also the amount (16.5 and $14.2 \mathrm{~mm}$ at 15

512 and 16 UTC, respectively). For the Morella-CHE station (15.8 mm; Fig. 9b), the hourly

513 maxima of precipitation occurring at $15 \mathrm{UTC}(4.6 \mathrm{~mm})$ and $16 \mathrm{UTC}(11.2 \mathrm{~mm})$ were

514 fairly reproduced by the HIR-D5 (2.3 mm at 16 UTC); the HIR-D2.5 detected two

515 peaks of precipitation at the time of this episode (4.7 and $3.4 \mathrm{~mm}$ at 15 and 16 UTC,

516 respectively) but incorrectly predicted precipitation during the rest of the day with a

517 maximum peak of rainfall at 22 UTC $(6.5 \mathrm{~mm})$. The HAR-D2.5 best represented this

518 episode, but with a maximum of $7.9 \mathrm{~mm}$ at $15 \mathrm{UTC}$, i.e., showing a timing error of one

519 hour before the observed maximum. Lastly, for the Michavilla-CHE station (8.2 mm;

520 Fig. 9c) again the HAR-D2.5 performed reasonably well for the hourly maximum of

521 precipitation observed at $15 \mathrm{UTC}$ (5.8 mm against $7.6 \mathrm{~mm}$ for the HAR-D2.5); whereas

522 the HIR-D2.5 overestimated the amount and timing with a peak of maximum

523 precipitation of $73.4 \mathrm{~mm}$ at $17 \mathrm{UTC}$; and the HIR-D5 captured an hourly maximum of

$5244.5 \mathrm{~mm}$ but one hour later than the observed event. Therefore, we can conclude that, for

525 this particular case, the HARMONIE was also able to perform better in terms of timing

526 in comparison with the HIRLAM set-ups. 
530 of non-parametric statistical methods may lead to unstable or poor results, due to the

531 paucity of the statistical sample. In addition, with high resolution models like the ones

532 applied here and with the operational forecasts increasing in resolution at the Weather

533 Services it is quite difficult to get good verification results, even when radar data are

534 available, due to the difficulty in matching between forecasts and observations.

535 However, here we show the neighborhood verification of the HAR-D2.5 as an example

536 of good forecast performance of the non-forecasted sea breeze thunderstorm that

537 occurred on 7 August 2008. The neighborhood verification of the HAR-D2.5

538 precipitation forecast against the maximum observed rain is shown in Figure 11. The

539 multi-event contingency table (Fig. 10a) displays strong HK scores for most rainfall

540 thresholds, and particularly for neighborhood sizes greater than $10-\mathrm{km}$. The pragmatic

541 approach (Fig. 10b) also reported positive BSS scores for most spatial scales and

542 rainfall thresholds. Lastly, the conditional square root of RPS method (Fig. 10c)

543 showed lower (better) than average values of CSRR. In general, the HARMONIE

544 forecast precipitation overlapped quite well with several observations of heavy rain,

545 demonstrating the ability of this model to reproduce isolated convection associated with

546 low-level convergence of sea breezes. 
In this study we investigated the ability of both the three-dimensional

hydrostatic grid-point HIRLAM model (5.0-km and 2.5-km grid-spacing set-ups) and the forthcoming operational non-hydrostatic spectral HARMONIE suite $(2.5-\mathrm{km})$ in predicting sea breeze thunderstorms that occurred over preferential convergence zones

554 in the eastern façade of the Iberian Peninsula, Spain. We simulated a set of 15 sea

555 breeze thunderstorms with intense convective activity that were not forecasted by the

556 operational HIRLAM system. Neighborhood or 'fuzzy' verification techniques were applied to this set of high resolution regional forecasts making use of high-density gridded raingauge measurements. The aim was to statistically compare the performance of HIRLAM and HARMONIE suites with different grid resolutions in predicting this dangerous sea breeze convective phenomena in the Mediterranean area of the Iberian

561 Peninsula.

The overall results revealed that both the more recent high resolution HIRLAM and the HARMONIE model succeeded in capturing the occurrence of these convective

564 showers, which were missed in the operational HIRLAM runs, with the HARMONIE model being most capable of delivering high quality forecasts of isolated convection associated with sea breezes in terms of amount, location, and also time. To summarize, it was found that the HIRLAM model at 5-km predicted light to moderate precipitation signals (weak overprediction bias) and a bit displaced in space; the HIRLAM model at 2.5-km simulated excessive amounts of rainfall (strong overprediction bias) for large areas, i.e., the precise location was not too accurate; whereas the HARMONIE suite at

$571 \quad 2.5-\mathrm{km}$ forecasted the precipitation in the right place at the right time with reasonable amount. It was therefore found that the performance of HARMONIE was better for the cases studied here as shown by the neighborhood verification metrics. Weusthoff et al.

574 (2010) also evaluated by means of 'fuzzy' techniques that high-resolution models give 
575 better results for more localized convective precipitation events, and Van der Plas et al.

576 (2012) found that higher precipitation intensities were better represented in the

577 HARMONIE model. versions and the experimental HIRLAM model at 5-km forecast are hypothetically caused by the coarser resolution of these HIRLAM versions, combined with the less developed physics in the operational AEMET runs of that time. Differences in predicting isolated convection found between the coarser HIRLAM versions and the highest resolution HIRLAM and HARMONIE set-ups can be linked to the impact of model grid resolution and therefore the ability to skillfully resolve sea breezes and local winds (Ries and Schlünzen, 2009), in combination with the absence of a deep convection parameterization in these cases. Different horizontal grid spacing schemes result in a different placement and strength of the sea breeze front since the temperature gradient is only a few kilometers wide (Atkins and Wakimoto, 1997). In theory, finer resolution allows much stronger horizontal gradients and updrafts at the sea breeze

590 front and a quicker development of convective showers, but sometimes even a $2.5-\mathrm{km}$

591 grid spacing is too coarse to simulate convection associated with sea breezes. Another effect of the higher resolution is that orography gradients become steeper, having a

593 direct impact on resolving the development of upslope winds. Furthermore, we found

594 that the overestimation bias for the HIRLAM forecasts can be partly explained by the

595 fact that the precipitation fall speed is infinity in the HIRLAM model suite, i.e.,

596 precipitation is put on the ground directly, which is quite normal in hydrostatic models. 
model, since it is better able to provide good estimates of the precipitation

600 accumulations and location of isolated convective events. This overall result confirms

601 the potential capability and skill of the forthcoming HARMONIE model as operational

602 for most European Weather Services to capture isolated showers and thunderstorms

603 associated with mesoscale / local winds in areas of complex terrain. This advance in

604 quantitative precipitation forecasting has practical applications for very short range

605 forecasting of local dangerous convective phenomena, which cause significant

606 economic damage and flooding in the Mediterranean area of the Iberian Peninsula

607 (Sánchez et al., 2003).

608

609 Acknowledgements

610 The authors wish to acknowledge the editor and two anonymous reviewers for

611 their detailed and helpful comments to the original manuscript. This research was

612 undertaken in the frame of the BEST/2010/014 (GV), the JAE-DOC043 (CSIC;

613 European Social Fund, FSE) and the JCI-2011-10263 grants. This research was

614 supported by the projects CGL2011-27574-C02-02 and CGL2011-27536/HID,

615 financed by the Spanish Commission of Science and Technology, and FEDER;

616 ACQWA (FP7-ENV- 2008-1-212250), financed by the European Comission; "Efecto

617 de los escenarios de cambio climático sobre la hidrología superficial y la gestión de

618 embalses del Pirineo Aragonés", financed by "Obra Social La Caixa”; and CTTP1/12

619 “Creación de un modelo de alta resolución espacial para cuantificar la esquiabilidad y

620 la afluencia turística en el Pirineo bajo distintos escenarios de cambio climático",

621 financed by the "Comunidad de Trabajo de los Pirineos". The authors would like to

622 thank the AEMET, CEAM, CHE, CHJ, IVIA, METEOCLIMATIC, SIAM, SIAR and 
623 SMC for raingauge data; and to José-Antonio García-Moya and Estrella Gutiérrez-

624 Marco (AEMET) for providing the HIRLAM 6.1.2 outputs.

625

626 References

627

628 Aguilar, E., Auer, I., Brunet, M., Peterson, T.C., Wieringa, J., 2003. Guidelines on

629 Climate Metadata and Homogenization. World Meteorol. Organ., 52 pp. [Available

630 online at http://www.wmo.int/datastat/documents/WCDMP-53_1.pdf] (last accessed

$631 \quad 1$ November 2013)

632 Atger, F., 2001: Verification of intense precipitation forecasts from single models and

633 ensemble prediction systems. Non. Proc. Geophy. 8, 401-417.

634 Atkins, N.T., Wakimoto, R.M., Weckwerth, T.M., 1995. Observations of the sea-breeze

635 front during CaPE. Part II: Dual-Doppler and aircraft analysis. Mon. Wea. Rev. 123,

$636944-969$.

637 Atkins, N.T., Wakimoto, R.M., 1997. Influences of the synoptic-scale flow on sea

638 breezes observed during CaPE. Mon. Wea. Rev. 125, 2112-2130.

639 Azorin-Molina, C., Martin-Vide, J., 2007. Methodological approach to the study of the

640 daily persistence of the sea breeze in Alicante (Spain). Atmosfera 20, 57-81.

641 Azorin-Molina, C., Guijarro, J.A., Baena-Calatrava, R., Jansà, A., 2007. Sea breeze

642 convergence and convective cloud frequencies from AVHRR data over Mallorca

643 Island. 7th EMS Annual Meeting/8th European Conference On Applications of 

EMS2007-A-00541

646 Azorin-Molina, C., Connell, B.H., Baena-Calatrava, R., 2009. Sea-breeze convergence 647 zones from AVHRR over the Iberian Mediterranean area and the Isle of Mallorca, $648 \quad$ Spain. J. Appl. Meteor. Climatol. 48, 2069-2085.

649 Baker, R.D., Lynn, B.H., Boone, A., Tao, W.-K., Simpson, J., 2001. The influence of 650 soil moisture, coastline curvature, and land-breeze circulations on sea-breeze 651 initiated precipitation. J. Hydromet. 2, 193-211.

652 Bechtold, P., Pinty, J.-P., Mascart, P., 1991. A numerical investigation of the influence 653 654

Blanchard D. O., López, R. E., 1985. Spatial patterns of convection in south Florida. 656 Mon. Wea. Rev. 113, 1282-1299.

657

Calvo, J., 2007. Kain-Fritsch convection in HIRLAM. Present status and prospects. Hirlam Newsletter 52, 57-64.

Dailey, P. S., Fovell, R.G., 1999. Numerical simulation of the interaction between the 660 sea-breeze front and horizontal convective rolls. Part I: Offshore ambient flow. $661 \quad$ Mon. Wea. Rev. 127, 858-878.

662 de Brujin, E. I. F., de Rooy, W. C., 2012. Evaluation of HARMONIE in the KNMI 663 parameterisation testbed. Adv. Sci. Res. 8, 167-170. 
664 Ebert, E.E., 2008. Fuzzy verification of high-resolution gridded forecasts: a review and 665 proposed framework. Meteorol. Appl. 15, 51-64.

666 Fovell, R.G., Dailey, P. S., 2001. Numerical simulation of the interaction between the 667 sea-breeze front and horizontal convective rolls. Part II: Alongshore ambient flow. 668 Mon. Wea. Rev. 129, 2057-2072.

Fovell, R.G., 2005. Convective initiation ahead of the sea-breeze front. Mon. Wea. Rev.

670 133, 264-278.

Germann, U., Zawadzki, I., 2004. Scale dependence of the predictability of precipitation from continental radar images. Part II: probability forecasts. J. Appl. Meteorol. 43, 74-89.

674 Gollvik, S., 2002. A snow model intended for HIRLAM. Proceedings of the SRNWP/HIRLAM Workshop on Surface Processes, Turbulence and Mountain Effects. Spanish Meteorological Agency, Madrid (Spain).

Gollvik, S., 2004. Surface modelling in Northern Europe. HIRLAM Baltic Workshop 678 Report, pp. 52-60.

679 González-Márquez, J., Heredia, M. A., 2001. Sea breeze convection in Mallorca. 680 Proceedings, V National Symposium of Forecasting, Madrid, Spain, Spanish 681 Meteorological Agency, pp. 1-6. (in Spanish)

682 Huang, X.-Y., Yang, X., Gustafsson, N., Mogensen, K., Lindskog, M., 2002. Four683 dimensional variational data assimilation for a limited area. HIRLAM Technical $684 \quad$ Report 57, 44 pp. 
685 Ivarsson, K.I., 2007. The Rasch-Kristjansson large scale condensation; present status 686 and prospects. Hirlam Newsletter 52, 50-56.

687 Kain, J.S., 2004. The Kain-Fritsch Convective Parameterization: An Update. J. Appl. $688 \quad$ Meteor. 43,170-181.

689 Kourzeneva, E., Samuelsson, P., Ganbat, G., Mironov, D., 2008. Implementation of 690 lake model FLake in HIRLAM. HIRLAM Newsletter 54, 54-61.

691 Mazarakis, N., Kotroni, V., Lagouvardos, K., Argiriou, A.A., 2009. The sensitivity of 692 numerical forecasts to convective parameterization during the warm period and the 693 use of lightning data as an indicator for convective occurrence. Atmos. Res. 94, $694 \quad 704-714$.

695 Millán, M. M., Estrela, M. J., Miró, J., 2005. Rainfall Components: Variability and 696 spatial distribution in a Mediterranean area (Valencia region). J. Climate 18, 26826972705.

698 Mironov, D. V., 2008. Parameterization of lakes in numerical weather prediction. 699 Description of a lake model. COSMO Technical Report, 11, Deutscher $700 \quad$ Wetterdienst, Offenbach am Main, Germany, 41 pp.

701 Muppa, S.K., Anandan, V.K., Amit Kesarkar, K., Vijaya Bhaskara Rao, S., Narasimha 702 Reddy, P. 2012 Study on deep inland penetration of sea breeze over complex terrain 703 in the tropics. Atmos. Res. 104-105, 209-216

704 Neumann, J., 1951. Land breezes and nocturnal thunderstorms. J. Meteor. 8, 60-67. 
705 Nicholls, M.E., Pielke, R.A., Cotton, W.R., 1991. A two-dimensional numerical

706 investigation of the interaction between sea breezes and deep convection over the

707 Florida Peninsula. Mon. Wea. Rev. 119, 298-323.

708 Noilhan, J., Planton, S., 1989. A simple parameterization of land surface processes for 709 meteorological models. Mon. Wea. Rev. 117, 536-549.

710 Papanastasiou, D.K., Melas, D., Lissaridis, I., 2010. Study of wind field under sea 711 breeze conditions; an application of WRF model. Atmos. Res. 98(1), 102-117.

712 Pérez-Landa, G., Ciais, P., Sanz, M.J., Gioli, B., Miglietta, F., Palau, J.L., Gangoiti, G., 713 Millán, M.M., 2006. Mesoscale circulations over complex terrain in the Valencia 714 coastal region, Spain, Part 1: simulation of diurnal circulation regimes. Atmos.

$715 \quad$ Chem. Phys. Discuss. 6, 2809-2852.

716 Petterssen, S., 1956. Weather Analysis and Forecasting, ed. McGraw-Hill Book 717 Company, New York.

718 Pielke, R.A., Song, A., Michaels, P.J., Lyons, W.A., Arritt, R.W., 1971. The

719 predictability of sea-breeze generated thunderstorms. Atmosfera 4, 65-78.

720 Pielke, R.A., 1974. A three-dimensional numerical model of the sea breezes over South $721 \quad$ Florida. Mon. Wea. Rev. 102, 115-139.

722 Pielke, R.A., Cotton, W.R., 1977. A mesoscale analysis over south Florida for a high 723 rainfall event. Mon. Wea. Rev. 105, 343-362. 
724 Pielke, T.A., Mahrer, Y., 1978. Verification analysis of the University of Virginia three725 dimensional mesoscale model prediction over south Florida for July 1, 1973. Mon. $726 \quad$ Wea. Rev. 106, 1568-1589.

727 Purdom, J. F. W., 1976. Some uses of high-resolution GOES imagery in the mesoscale 728 forecasting of convection and its behavior. Mon. Wea. Rev. 104, 1474-1483.

729 Ries, H., Heinke Schlünzen, K., 2009. Evaluation of a mesoscale model with different 730 surface parameterizations and vertical resolutions for the Bay of Valencia. Mon. $731 \quad$ Wea. Rev. 137, 2646-2661.

732 Rontu, L., Sattler, K., Sigg, R., 2002. Parametrization of subgrid-scale orography effects 733 in HIRLAM. Technical Report 56, 46 pp.

734 Sánchez, J.L., Fernández, M.V., Fernández, J.T., Tuduri, E., Ramis, C., 2003. Analysis 735 of mesoscale convective systems with hail precipitation. Atmos. Res. 67-68, 573736588.

737 Savijärvi, H., 1990. Fast radiation parameterization schemes for mesoscale and short738 range forecast models. J. Appl. Meteor. 29, 437-447.

739 Seity, Y., Brousseau, P., Malardel, S., Hello, G., Bénard, P., Bouttier, F., Lac, C., 740 Masson, V., 2011. The AROME-France Convective-Scale Operational Model. Mon. $741 \quad$ Wea. Rev. 139, 976-991.

742 Simpson, J.E., 1994. Sea breeze and local wind, ed. Cambridge University Press, New $743 \quad$ York. 
744 Simpson, M., Warrior, H., Raman, S., Aswathanarayana, P.A., Mohanty, U.C., Suresh, 745 R., 2007. Sea-breeze-initiated rainfall over the east coast of India during the Indian 746 southwest monsoon. Nat. Hazards 42, 401-413.

747 Strickler, M. W., 2003. Sea-Breeze Fronts and Their Role in Convective Initiation.

748 North Carolina State University, Raleigh, North Carolina, 22 pp.

Tartaglione, N., Mariani, S., Accadia, C., Speranza, A., Casaioli, M., 2005. Comparison of rain gauge observations with modeled precipitation over Cyprus using Contiguous Rain Area analysis. Atmos. Chem. Phys. 5, 2147-2154.

Theis, S.E., Hense, A., Damrath, U., 2005. Probabilistic precipitation forecasts from a deterministic model: a pragmatic approach. Meteorol. Appl. 12, 257-268.

Tijm, A.B.C, Lenderink, G., 2003. Characteristics of CBR and STRACO versions. HIRLAM Newsletter 43, 115-124.

Undén, P., Rontu, L., Calvo, J., Cats, G., Cuxart, J., Eerola, K., Fortelius, C., GarciaMoya, J.A., Gustafsson, N., Jones, C., Järvenoja, S., Järvinen, H., Lynch, P., McDonald, A., McGrath, R., Navascues, B., Odegaard, V., Rodriguez, E., Rummukainen, M., Room, R., Sattler, K., Savijärvi, H., Sass, B.H., Schreur, B.W., The, H., Tijm, S., 2002. The HIRLAM-5 scientic documentation. HIRLAM-5 project. SMHI, S-60176, Norrköping, Sweden, 144 pp.

Van der Plas, E. V., Wichers Schreur, B., Kok, K., 2012. A quantitative evaluation of the high resolution HARMONIE model for critical weather phenomena. Adv. Sci. Res. 8, 149-155. 
765 Wakimoto, R. M., Atkins, N.T., 1994. Observations of the sea breeze front during

766 CAPE. Part I: Single Doppler, satellite, and cloud photogrammetry analysis. Mon.

767 Wea. Rev. 122, 1092-1114.

768 Weusthoff, T., Ament, F., Arpagaus, M., Rotach, M.W., 2010. Assessing the Benefits of 769 Convection-Permitting Models by Neighborhood Verification: Examples from MAP 770 D-PHASE. Mon. Wea. Rev. 138, 3418-3433.

771 Weusthoff, T., 2011. Neighbourhood verification in space and time. $5^{\text {th }}$ Intl. Verification Methods Workshop, 1-6 Dec. 2011, Melbourne, Australia.

773 Wilks, D.S., 2011. Statistical Methods in the Atmospheric Sciences. 3rd Edition.

$774 \quad$ Elsevier Inc.

775 Wilson, P.H., 2008. Warm-season lake-/sea-breeze severe weather in the Northeast.

776 Master thesis, Department of Earth and Atmospheric Sciences, University at 777 Albany, State University of New York, 115 pp.

778 Zhang, M., Lin, W., Bretherton, C.S., Hack, J.J., Rasch, P.J., 2003. A modified

779 formulation of fractional stratiform condensation rate in the NCAR community

780 atmospheric model (CAM2). J. Geophys. Res. - Atmos. 108, 4035,

781 doi:10.1029/2002JD002523. 
784

785 Table 1. Sea breeze thunderstorms selected for verifying the precipitation performance

786 of the HIRLAM and the HARMONIE models suites. The number of raingauge points,

787 the maximum of precipitation and location of this event are tabulated for each episode.

788

\begin{tabular}{|c|c|c|c|}
\hline Date & $\mathrm{N}^{\circ}$ Raingauges & $\begin{array}{l}\text { MaximumPrecip. } \\
(\mathrm{mm})\end{array}$ & Station \\
\hline $31 / 08 / 2001$ & 450 & 57.5 & Villena (A) \\
\hline $19 / 04 / 2002$ & 380 & 22.2 & Beneixama (A) \\
\hline $29 / 09 / 2002$ & 420 & 31.0 & Fontanars $(\mathrm{V})$ \\
\hline $18 / 06 / 2003$ & 423 & 13.9 & Mosqueruela (T) \\
\hline $25 / 08 / 2003$ & 424 & 3.1 & Alcora (C) \\
\hline $02 / 06 / 2004$ & 361 & 12.0 & Talave (AB) \\
\hline $20 / 06 / 2004$ & 363 & 90.0 & Pina $(\mathrm{C})$ \\
\hline $21 / 06 / 2004$ & 361 & 36.0 & Fredes $(\mathrm{C})$ \\
\hline $12 / 08 / 2005$ & 363 & 1.7 & $\operatorname{Ibi}(\mathrm{A})$ \\
\hline $28 / 09 / 2006$ & 356 & 25.0 & Pinoso (A) \\
\hline $08 / 10 / 2007$ & 350 & 35.0 & Ibi (A) \\
\hline $01 / 08 / 2008$ & 323 & 34.0 & Villafranca $(\mathrm{C})$ \\
\hline $07 / 08 / 2008$ & 533 & 45.0 & Cati $(\mathrm{C})$ \\
\hline $08 / 08 / 2008$ & 325 & 53.7 & Relleu (A) \\
\hline $11 / 09 / 2009$ & 304 & 43.0 & Cati (C) \\
\hline
\end{tabular}

789

790 (A) Alicante province, (AB) Albacete province, (C) Castellon province, (T) Teruel province, and (V)

791 Valencia province. The (C) and (T) regions correspond to areas affected by the SBCZ2 (Iberian system

792 mountains) and the (A) and (V) regions by the SBCZ3 (Prebetic mountain ranges)

793 
796 Table 2. Optimal scale (in $\mathrm{km}$ ) and the HK score found for all three NWP models as a

797 function of the rain intensity thresholds (in $\mathrm{mm}$ ).

\begin{tabular}{|c|c|c|c|c|c|c|c|c|}
\hline \multirow{2}{*}{\multicolumn{2}{|c|}{ Model suite }} & \multicolumn{7}{|c|}{ Rain threshold (in mm) } \\
\hline & & 0.2 & 1.0 & 2.0 & 5.0 & 10.0 & 20.0 & $50.0^{*}$ \\
\hline \multirow{2}{*}{ HIR-D2.5 } & Scale & 2.5 & 2.5 & 17.5 & 37.5 & 37.5 & 37.5 & 17.5 \\
\hline & $\mathrm{HK}$ & 0.34 & 0.38 & 0.40 & 0.52 & 0.57 & 0.54 & 0.32 \\
\hline \multirow{2}{*}{ HIR-D5 } & Scale & 5.0 & 25.0 & 55.0 & 65.0 & 65.0 & 85.0 & --- \\
\hline & $\mathrm{HK}$ & 0.31 & 0.40 & 0.45 & 0.49 & 0.35 & 0.16 & 0 \\
\hline \multirow{2}{*}{ HAR-D2.5 } & Scale & 7.5 & 22.5 & 22.5 & 27.5 & 22.5 & 27.5 & 37.5 \\
\hline & HK & 0.37 & 0.45 & 0.45 & 0.53 & 0.59 & 0.59 & 0.63 \\
\hline
\end{tabular}

798 *There were only 3 observations of $50 \mathrm{~mm}$ or more.

799

800

801

802

803

804

805

806

807

808

809 
810 Table 3. As in Table 2 but for the BSS scores.

\begin{tabular}{|c|c|c|c|c|c|c|c|c|}
\hline \multirow{2}{*}{\multicolumn{2}{|c|}{ Model suite }} & \multicolumn{7}{|c|}{ Rain threshold (in mm) } \\
\hline & & 0.2 & 1.0 & 2.0 & 5.0 & 10.0 & 20.0 & $50.0^{*}$ \\
\hline \multirow{2}{*}{ HIR-D2.5 } & Scale & 97.5 & 97.5 & 97.5 & 97.5 & 97.5 & 92.5 & 97.5 \\
\hline & $\mathrm{BSS}$ & -5.11 & -2.52 & -1.69 & -1.16 & -0.59 & -0.16 & -0.03 \\
\hline \multirow{2}{*}{ HIR-D5 } & Scale & 95 & 95 & 95 & 95 & 95 & 95 & 65 \\
\hline & BSS & -3.55 & -1.40 & -0.83 & -0.34 & -0.10 & -0.01 & 0 \\
\hline \multirow{2}{*}{ HAR-D2.5 } & Scale & 97.5 & 97.5 & 97.5 & 97.5 & 92.5 & 87.5 & 97.5 \\
\hline & BSS & -0.48 & -0.18 & -0.12 & -0.15 & -0.10 & -0.02 & -0.03 \\
\hline
\end{tabular}

$811 *$ There were only 3 observations of $50 \mathrm{~mm}$ or more.

812

813

814

815

816

817

818

819

820

821

822 


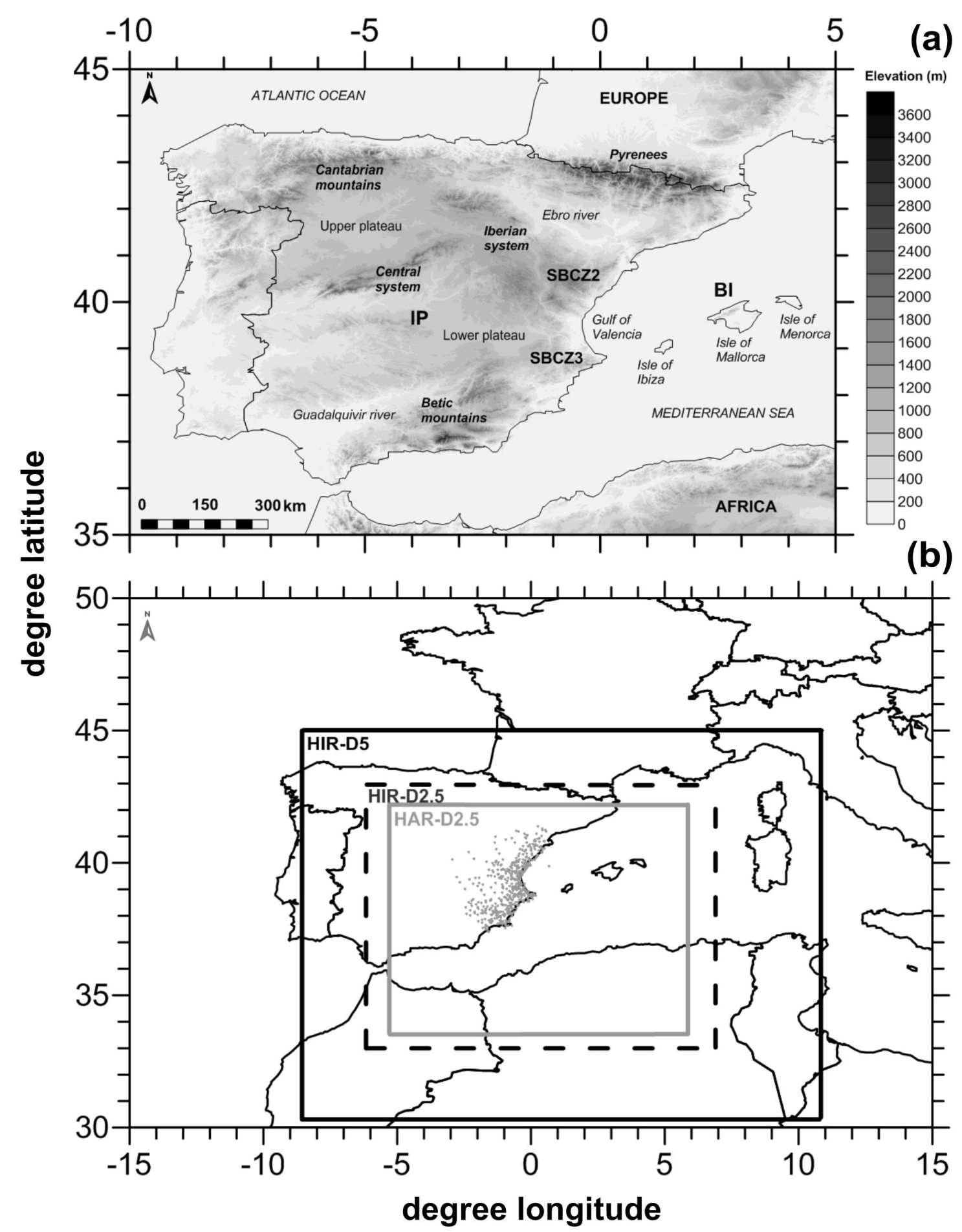

826 FIG. 1. (a) Terrain map of the Iberian Peninsula showing the complex topography of the

827 study area focussed on the steep Iberian System mountains (SBCZ2) and the Prebetic

828 mountains (SBCZ3). Specific locations cited to in the text and the most important 
829 geographical features of the IP are shown on the map. (b) HIRLAM model

830 configuration showing a largest (HIR-D5; black solid line) and smallest (HIR-D2.5;

831 black dashed line) domain with horizontal grid lengths of 5.0-km and 2.5-km,

832 respectively, and also displaying the HARMONIE model configuration with a domain

833 of 2.5-km grid spacing (HAR-D2.5; grey solid line). The map shows location (grey

834 dots) of the high-density rain-gauge network for verification model output.

835

836

837

838

839

840

841

842

843

844

845

846

847 


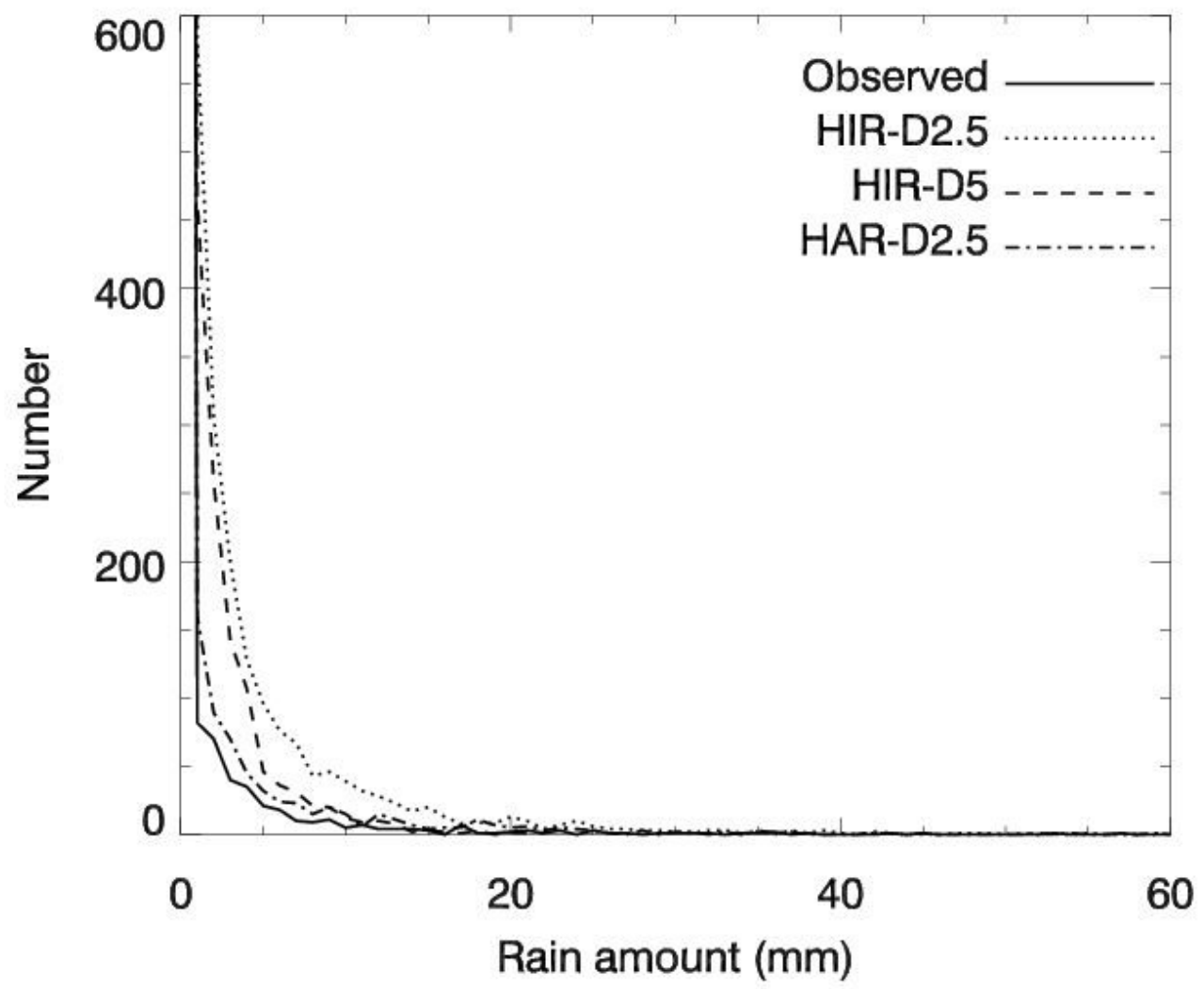

848

849 FIG. 2. Rain distribution from gridpoint match-ups using maximum observation in grid

850 box, pooled over all 15 non-forecasted sea breeze thunderstorms in the dataset.

851

852

853

854

855

856 

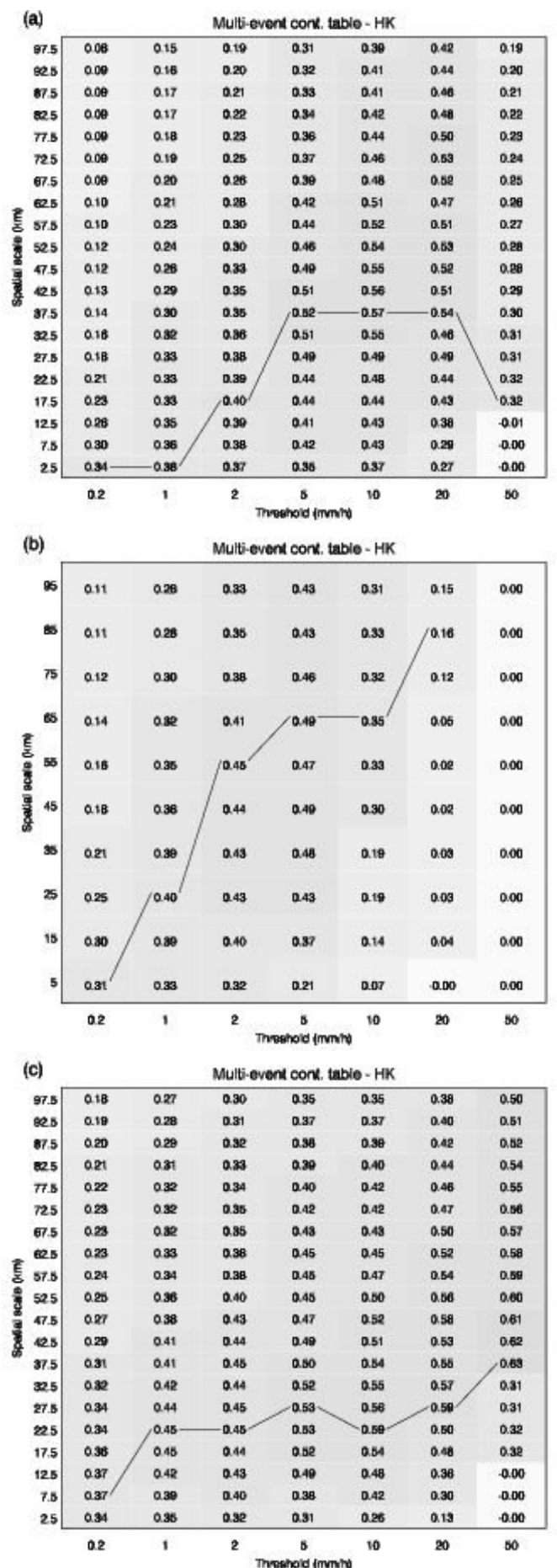

858 FIG. 3. Quilt plots of the HK scores as a function of different rain intensity threshold

$859(0.2,1.0,2.0,5.0,10.0,20.0$ and $50.0 \mathrm{~mm})$ and neighborhood sizes (from 2.5 up to

860 97.5-km) for (a) the HIR-D2.5, (b) the HIR-D5 and (c) the HAR-D2.5. The darker and

861 lighter shades show good or poor model performance, respectively. The lines indicate 862 the better scale at each rain threshold. 

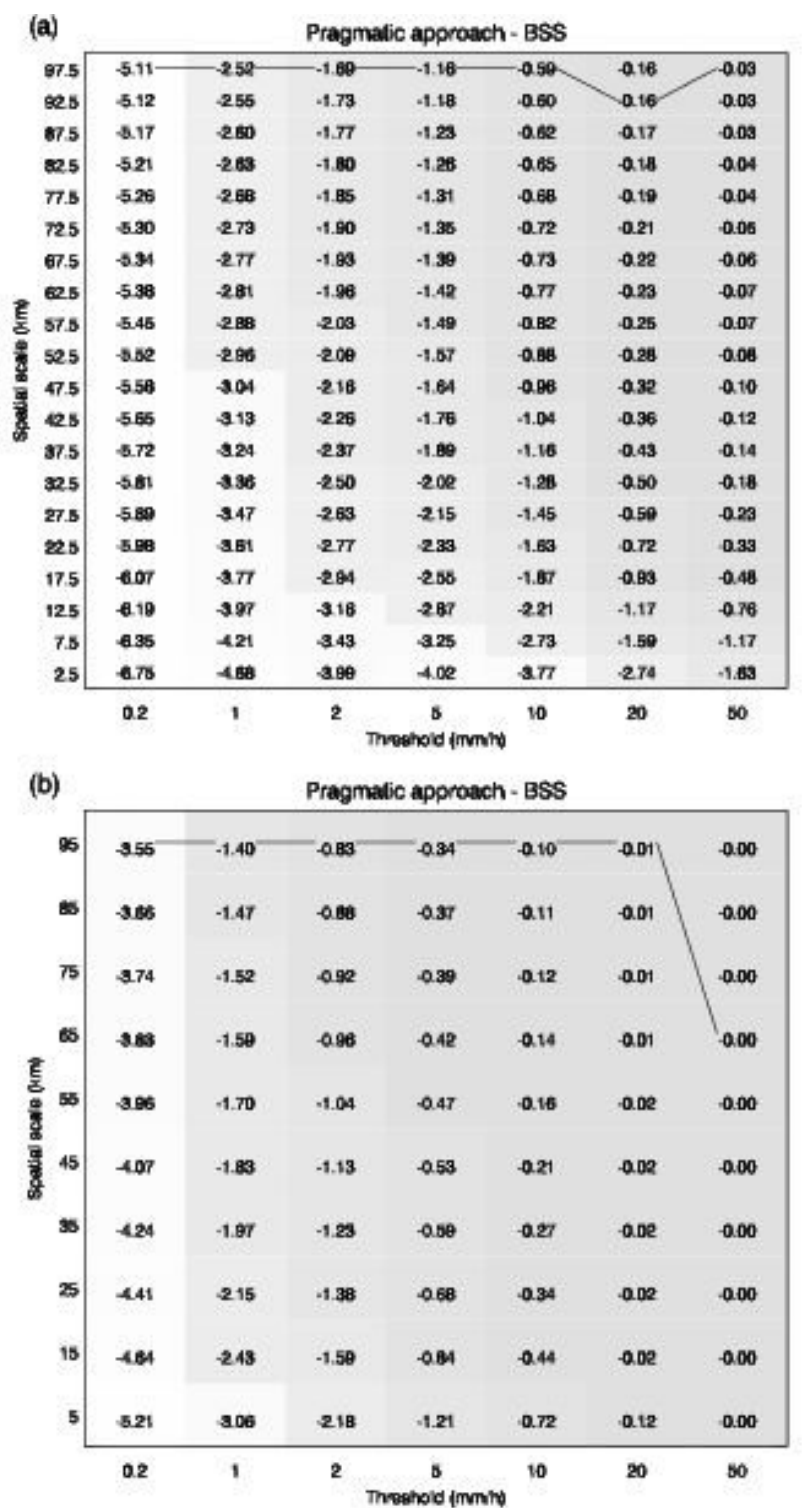

\begin{tabular}{|c|c|c|c|c|c|c|c|}
\hline \multirow{2}{*}{ (c) } & \multicolumn{7}{|c|}{ Pragmatic approach - BSS } \\
\hline & 0.48 & -0.18 & -0.12 & -0.15 & a.10 & -0.02 & -0.09 \\
\hline ses & 0.49 & Q1B & 0.12 & 0.15 & 0.10 & .0 .02 & 0.04 \\
\hline 87.5 & 0.81 & 0.18 & a.s & e.16 & a.10 & $0.0 e$ & 0.04 \\
\hline 225 & 0.52 & 0.19 & 0.13 & -0.18 & $-a .10$ & -0.02 & 0.05 \\
\hline$\pi 7.5$ & 0.54 & 0.20 & 0.14 & 0.17 & a.11 & 0.02 & 0.05 \\
\hline 725 & 0.87 & 021 & Q.15 & e.18 & 0.12 & 0.03 & 0.06 \\
\hline 67.5 & 0.50 & 022 & Q.18 & -0.18 & -0.12 & -0.03 & -0.07 \\
\hline 625 & 0.81 & 0.23 & - 117 & -0.19 & -0.12 & -0.03 & 0.08 \\
\hline 57.5 & OBA & 0.25 & Q.19 & 0.21 & 0.14 & 0.06 & 0.08 \\
\hline 525 & 0.87 & 021 & -0.20 & -023 & $-a .16$ & -0.07 & -0.10 \\
\hline 47.5 & 070 & 0.28 & -0.22 & 025 & - .19 & -0.06 & 0.12 \\
\hline ess & e.73 & 031 & .024 & .027 & 0.21 & -2.10 & 0.16 \\
\hline 37.5 & $2 \pi$ & 036 & 0.28 & -0.30 & 0.24 & a.12 & 0.16 \\
\hline 32.5 & .0 .82 & 0.39 & -0.32 & -0.34 & -0.28 & -0.15 & -0.18 \\
\hline 27.5 & 0.88 & 0.44 & 0.37 & 0.41 & -0.34 & 0.18 & 0.18 \\
\hline 225 & 0.96 & Q.50 & 0.43 & -0.50 & 0.43 & 0.23 & 0.21 \\
\hline 17.5 & -104 & -0.56 & -0.52 & -0.62 & -0.57 & -0.34 & -0.28 \\
\hline 125 & -1.18 & 070 & -0.63 & $\theta n$ & $a n$ & -0.51 & 0.038 \\
\hline 7.5 & -1.38 & 086 & QB日o & $Q B R$ & -1.03 & 0.79 & 0.61 \\
\hline 25 & -1.78 & -1.20 & -1.14 & -1.33 & -1.61 & -1.49 & .1 .24 \\
\hline & 0.2 & 1 & 2 & $B$ & 10 & 20 & 50 \\
\hline
\end{tabular}

864 FIG. 4. As in Figure 3 but for the BSS computed for the pragmatic method. 


\section{Conditional square root of RPS}

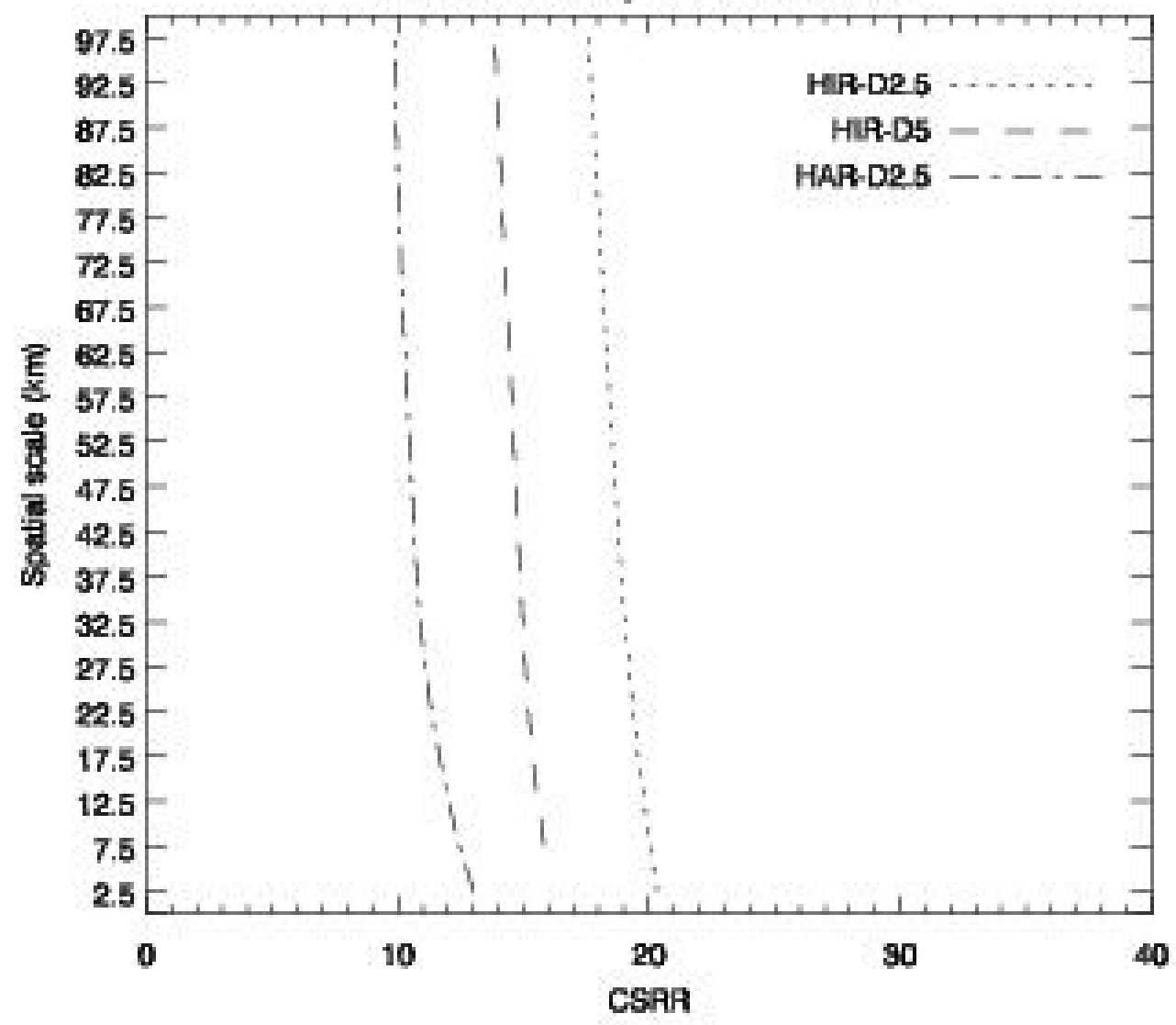

865

866 FIG. 5. Conditional square root of the RPS showing the CSRR metric as a function of

867 different window sizes (from 2.5 up to $97.5-\mathrm{km}$ ). 


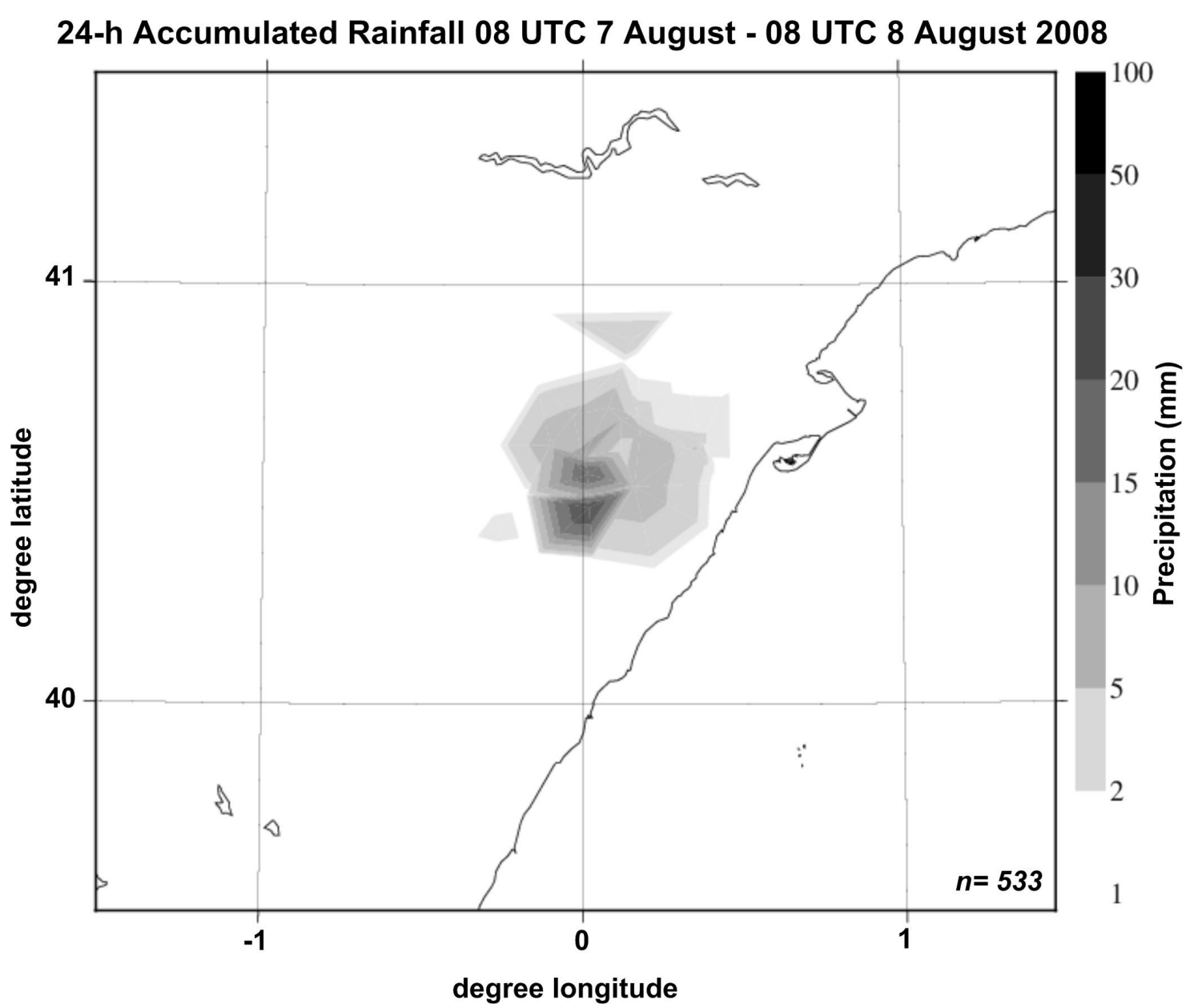

869 FIG. 6. Accumulated rainfall recorded between 08 UTC 7 August 2008 till 08 UTC 8

870 August 2008. The high spatial density of measurements ( $n=$ sample size) was obtained

871 by combining data from Hellmann (SYNOPS) and tipping bucket rain-gauges

872 (automatic weather station; AWS). The map was produced using a Kriging

873 interpolation. 


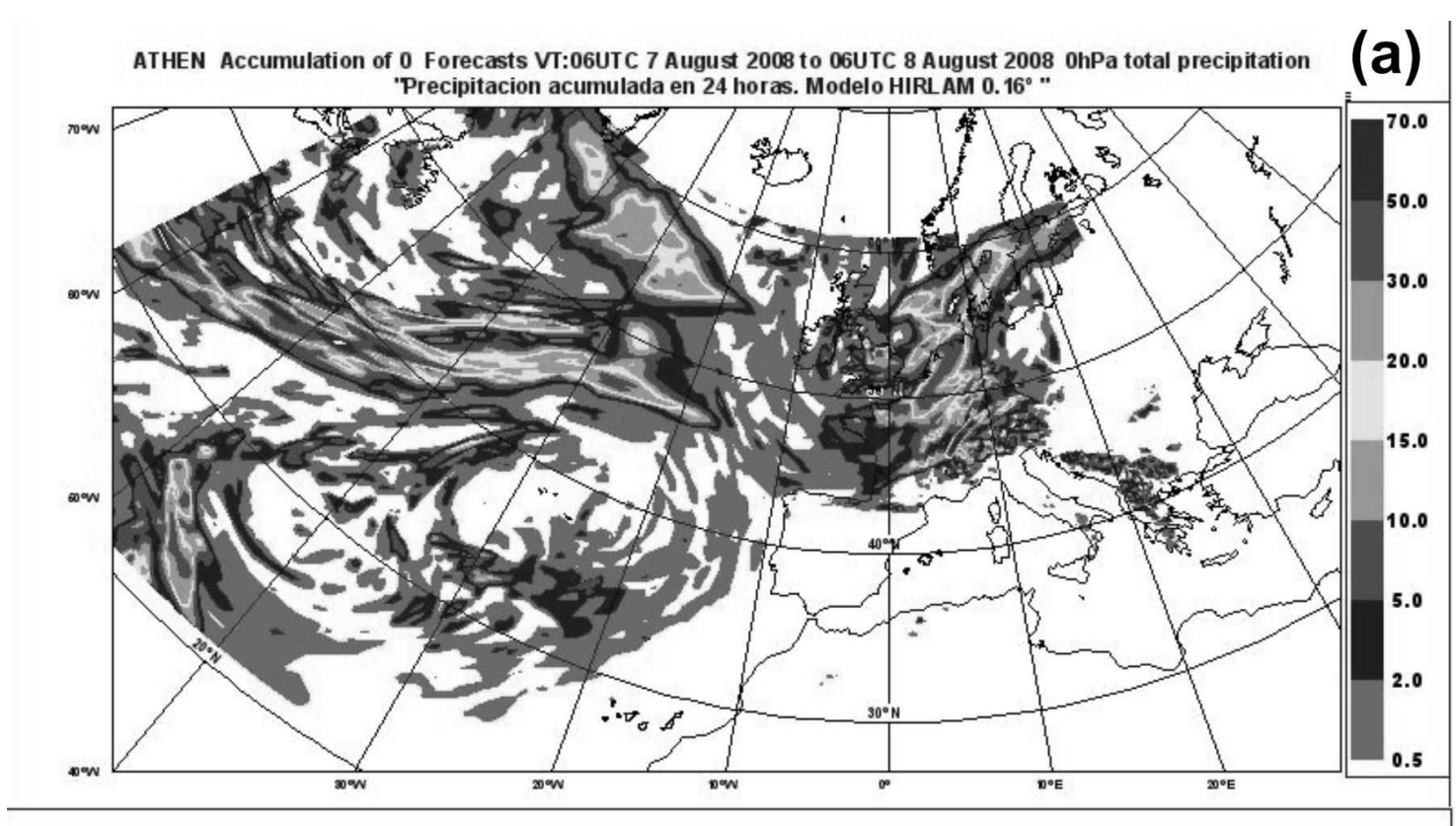

ATHEN Accumulation of 0 Forecasts VT:06UTC 7 August 2008 to 06UTC 8 August 2008 0hPa total precipitation

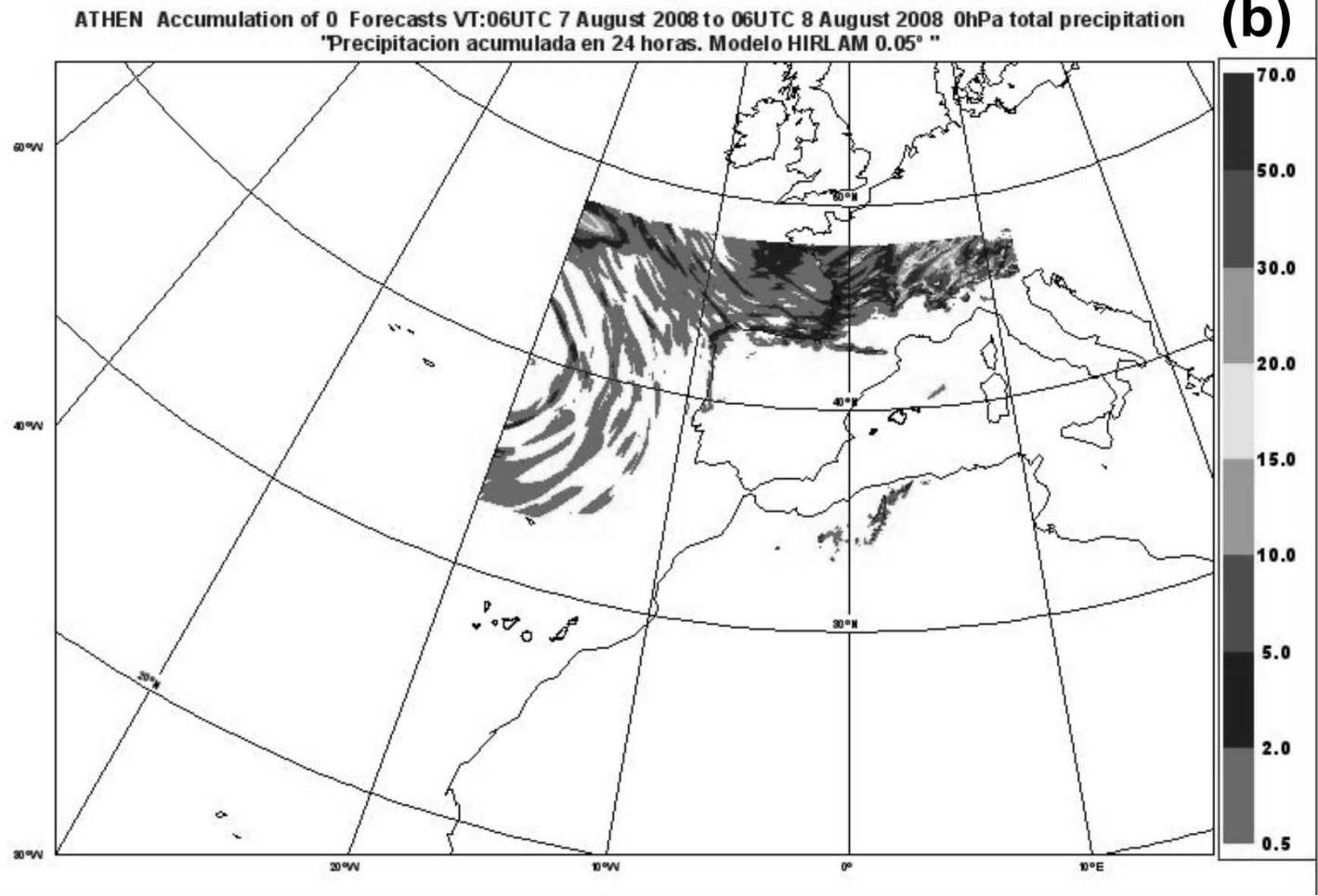

FIG. 7. 24-h accumulated rainfall between 06 UTC 7 August 2008 till 06 UTC 8 August

8762008 simulated from (a) the HIR-D16 (0.16 , i.e., 16-km length) and (b) the HIR-D5

$877\left(0.05^{\circ}\right.$, i.e., $5-\mathrm{km}$ length $)$ operational HIRLAM 6.1.2 version from the AEMET. 


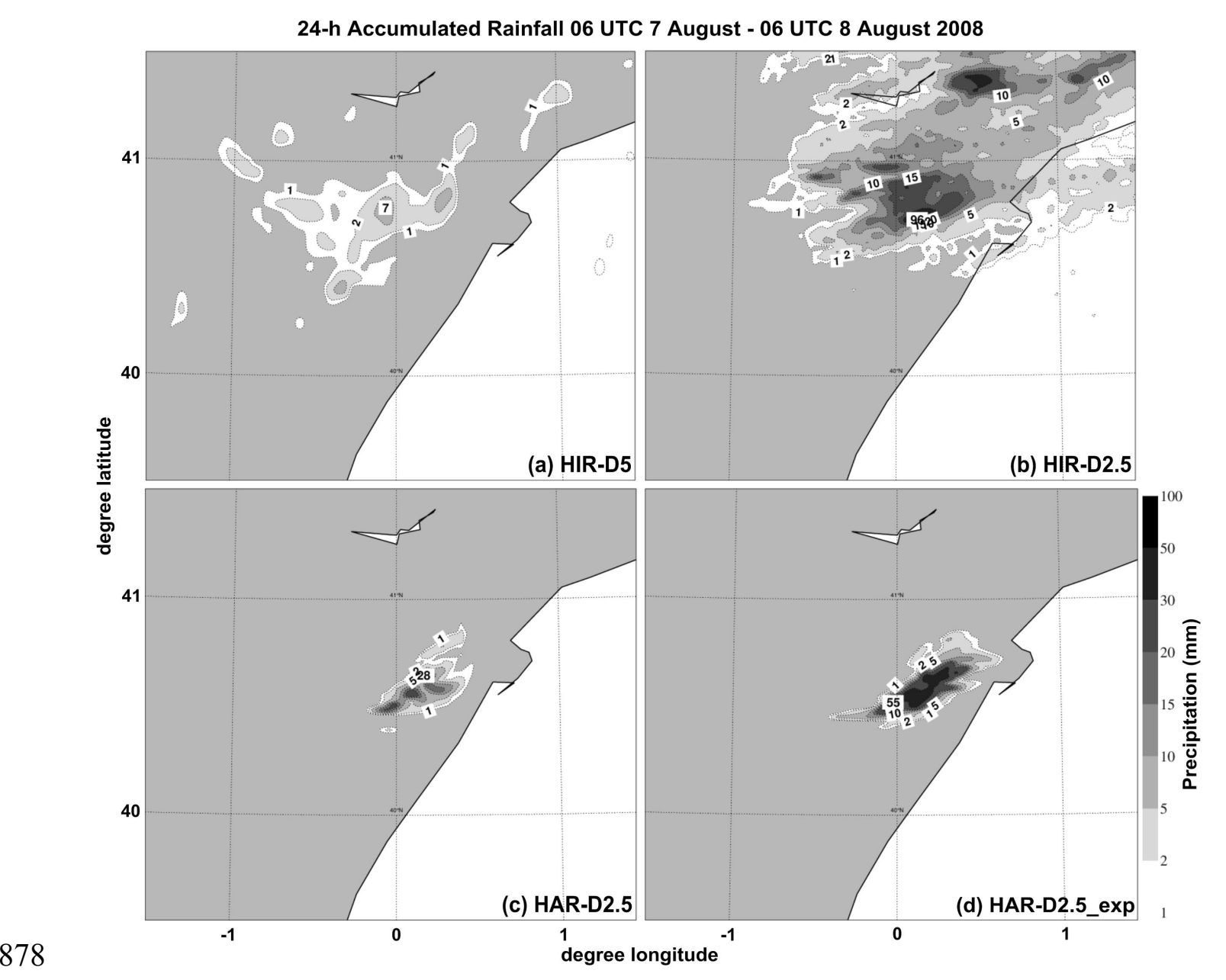

879 FIG. 8. 24-h accumulated rainfall between 06 UTC 7 August 2008 till 06 UTC 8 August

8802008 simulated from (a) the HIR-D5, (b) the HIR-D2.5, (c) the HAR-D2.5, and (d) the

881 HAR-D2.5_exp with an increase in fall speed of precipitation by a factor of 5. Note that

882 forecasted maps are plotted using the same boundaries and colors for comparison

883 against the observed rainfall map shown in Figure 6.

884

885

886

887 
10-m wind field at 12 UTC 7 August 2008

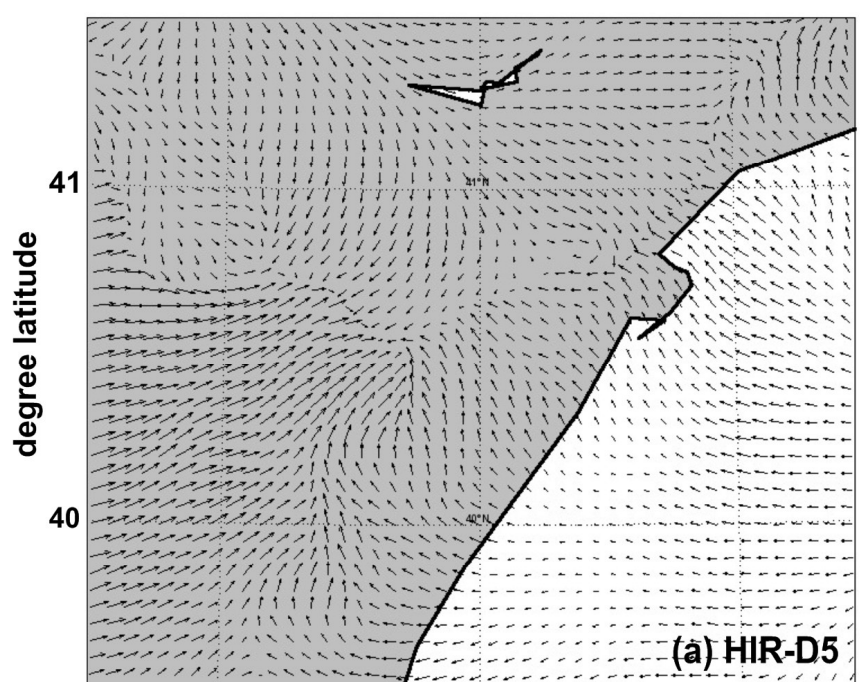

$-1$

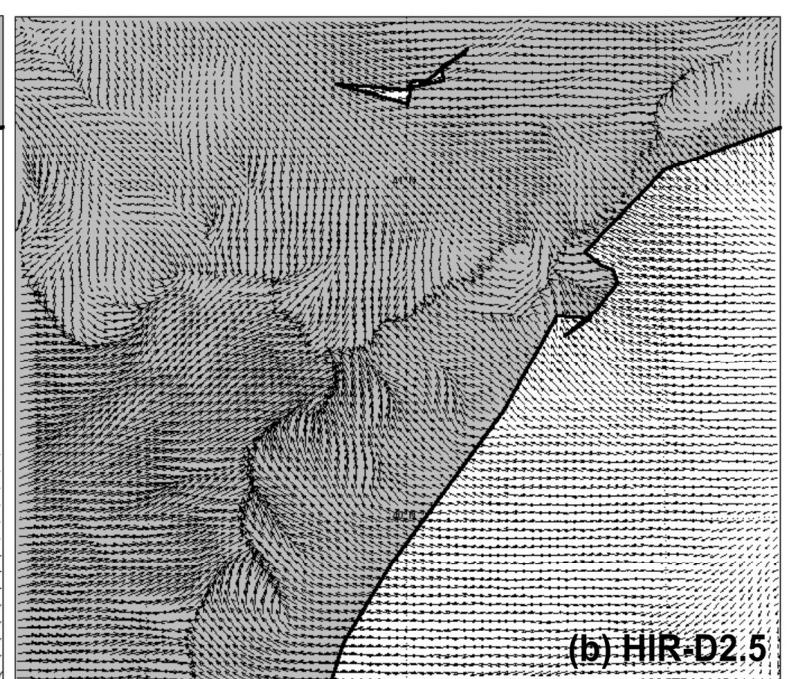

$-1$

degree longitude

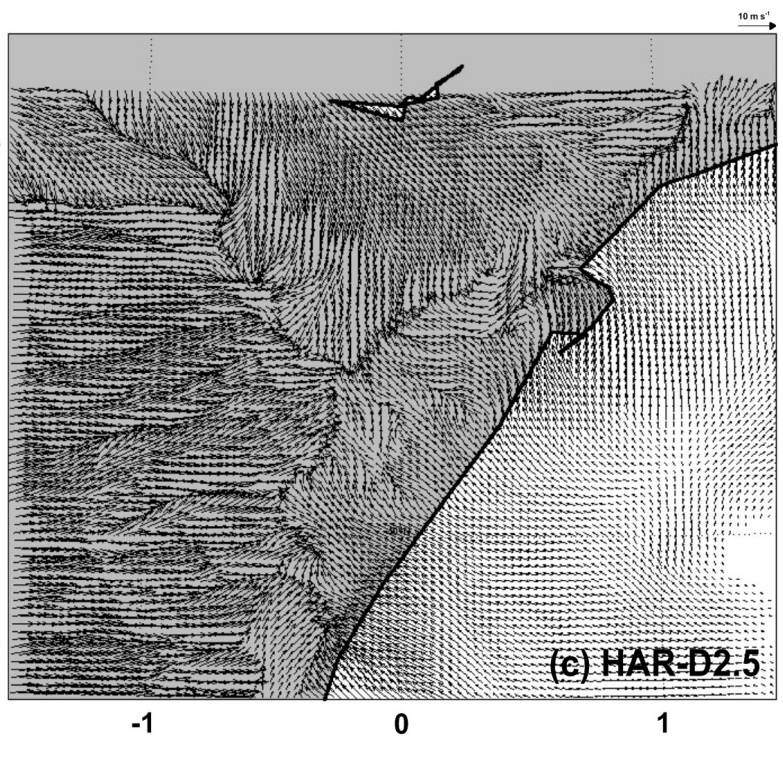

889 FIG. 9. 10-m wind vector simulated by (a) the HIR-D5, (b) the HIR-D2.5, and (c) the HAR-D2.5 at 12 UTC on 7 August 2008. 
(a) $\quad 40.55 \mathrm{~N}-0.02 \mathrm{E}$ (Vallivana - CEAM)
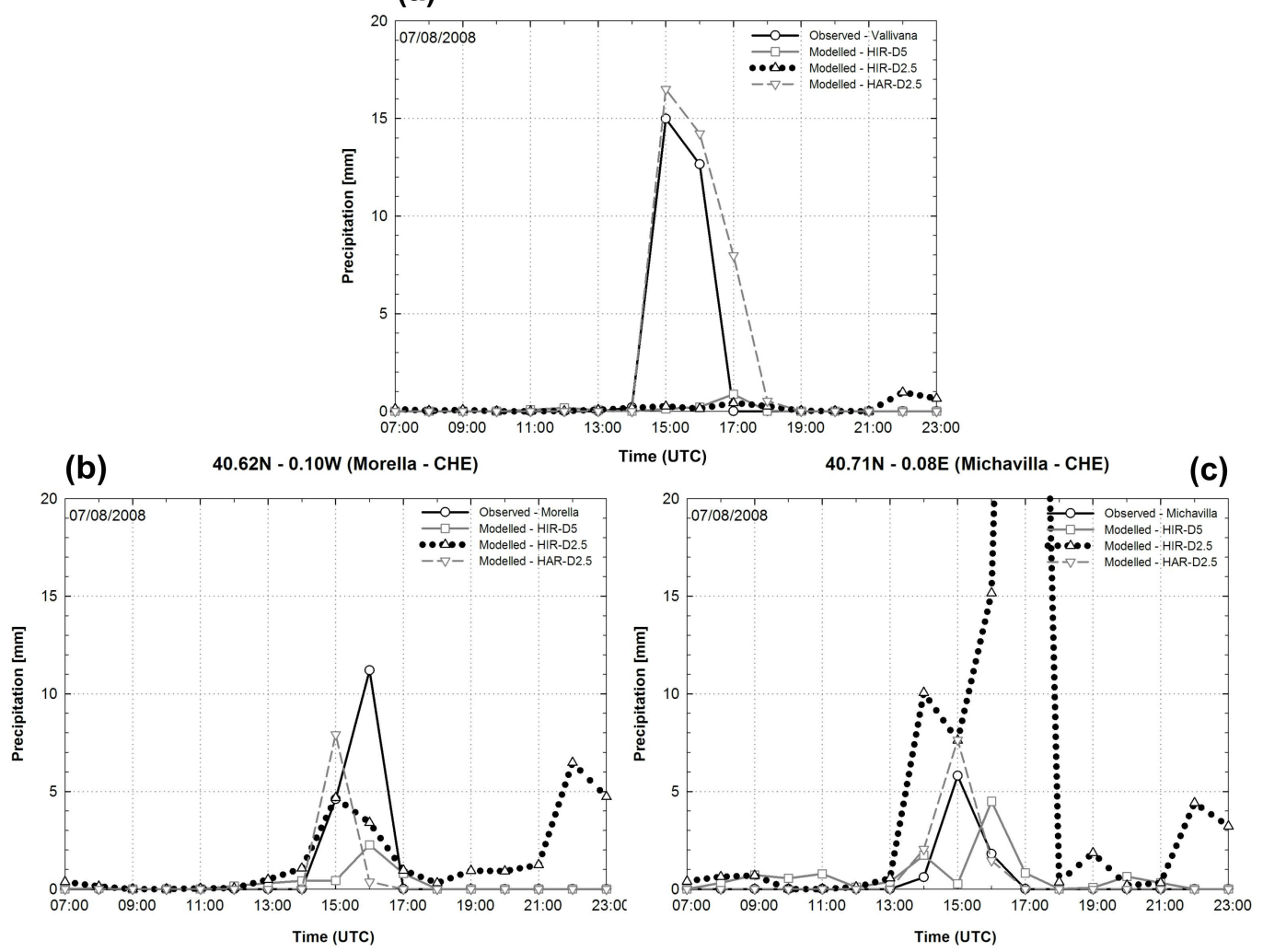

891 FIG. 10. Time series of observed and modelled precipitation in (a) Vallivana-CEAM,

892 (b) Morella-CHE and (c) Michavilla-CHE from 0700 till 2300 UTC on 7 August 2008.

893 The modelled values shown here correspond to the maximum precipitation in area with

894 radius of 5-km around raingauge station. Note that modelled precipitation for HIR-D2.5

895 exceeds the maximum y-axis for the Michavilla-CHE station. 

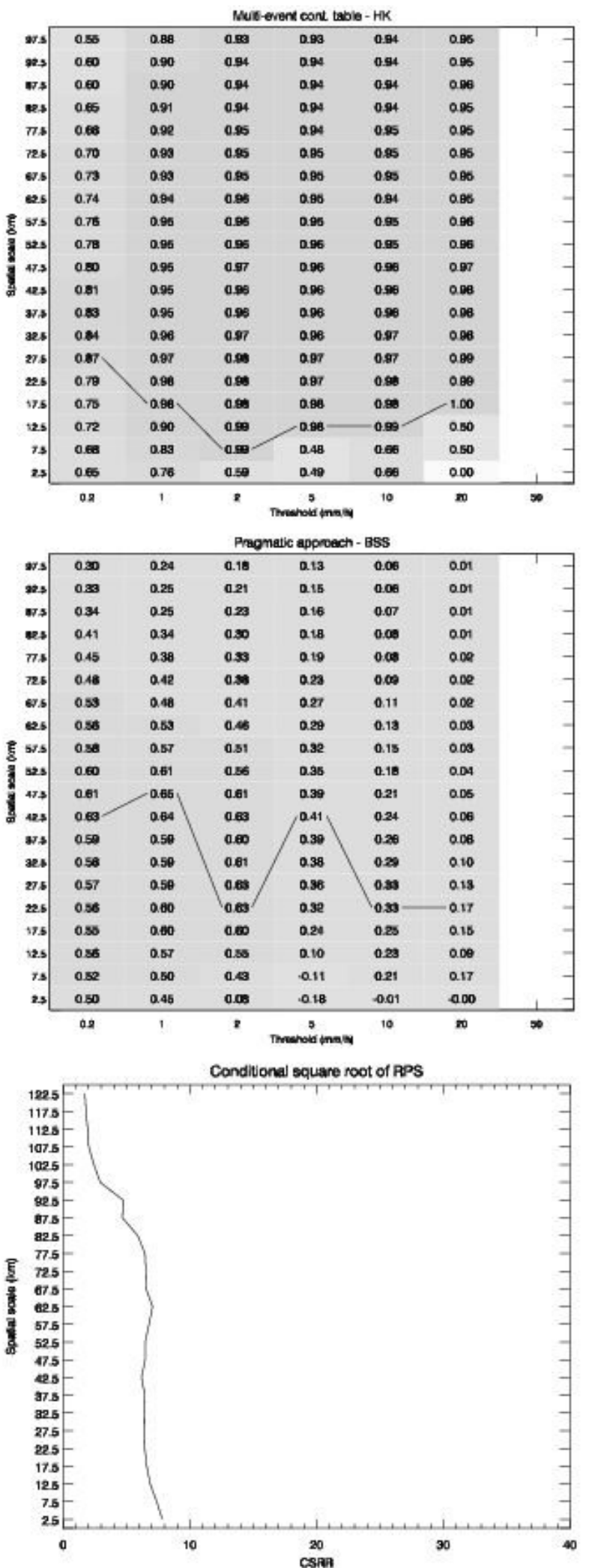

897 FIG. 11. Neighborhood verification of the forecast performed by the HAR-D2.5 on 7

898 August 2008 for (a) the HK scores and (b) the BSS metrics as a function of different 
899 rain intensity threshold $(0.2,1.0,2.0,5.0,10.0,20.0$ and $50.0 \mathrm{~mm})$ and neighborhood

900 sizes (from 2.5 up to $97.5-\mathrm{km}$ ), and (c) the CSRR scores as a function of different

901 window sizes (from 2.5 up to $122.5-\mathrm{km}$ ). The quilt plots of the HK and the BSS metris

902 show in darker and lighter shades good or poor model performance, respectively. The

903 lines indicate the better scale at each rain threshold.

904

905

906

907

908

909

910 